\title{
A Usability Evaluation of Academic Virtual Reference Services
}

\section{Anthony S. Chow and Rebecca A. Croxton}

This study examined the usability of five virtual reference services-instant messenger chat, e-mail, telephone, text messaging, and Skype videoconferencing - by having 31 undergraduate and graduate students evaluate the usability of the virtual reference services of two different universities. The study's results suggest that user preference and satisfaction for virtual reference service are highly correlated with the service's overall usability in terms of effectiveness and efficiency. Online chat was rated highest across all measures including satisfaction and seven different usability factors. Major implications of the study suggest that online chat is the virtual reference of choice for university students and that usability metrics are a good predictor of user preferences centered on high return on investment, speed of transaction, convenience, and minimal effort.

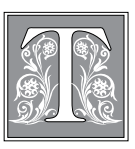

o stay relevant in this rapidly evolving information age, libraries across the world are racing to reinvent themselves.

They must do so in an environment where information seekers have "...many options, little patience, and use many different types of information and communication technology." ${ }^{11}$ While many libraries are increasingly making their content available digitally over the Internet, they are also taking steps to make their reference services available virtually. Some virtual reference services, including email, instant messaging (online chat), and telephone have been around for decades, while other services such as text messaging and videoconferencing are just beginning to emerge. Sloan reported that e-mail reference has been going strong for 20 years and live chat-based reference for 10 years. ${ }^{2}$ Virtual reference services are becoming commonplace in both academic and public libraries across the United States. In a recent survey study of 1,226 academic and public libraries, 54.95 percent of survey respondents indicated they offer reference services virtually. In a separate phase of this study, the researchers found that 84.6 percent $(n=203)$ of library websites evaluated offered virtual reference services. ${ }^{3}$ The most common type of virtual reference was e-mail reference, followed by chat, then text, then "other." Both surveys found the least used form of virtual reference was Skype or video conferencing.

While many libraries now offer a suite of virtual reference services, the proliferation of these services is not always matched by actual use. ${ }^{4}$ Many virtual

Anthony S. Chow is Associate Professor in the Department of Library and Information Studies of the School of Education at The University of North Carolina at Greensboro; e-mail: aschow@uncg.edu. Rebecca A. Croxton is a Doctoral Student and Instructor at The University of North Carolina at Greensboro; e-mail: racroxto@uncg.edu. (C) 2014 Anthony S. Chow and Rebecca A. Croxton, Attribution-NonCommercial (http://creativecommons.org/licenses/by-nc/3.0/) CC BY-NC 
reference projects initiated in recent years have been suspended or discontinued altogether. Several studies suggest the success of virtual reference services does not depend solely on the quality of the service but may also be dependent upon funding, volume of reference questions, staffing levels, hardware and software issues, and institutional culture. ${ }^{5}$ Further, many library patrons are not aware that virtual reference services are available. ${ }^{6}$

While many elements contribute to a person's experience using a virtual reference service, a significant yet often overlooked factor is the overall usability of the digital services. Chow explains, “...digital environments are for human use, and taking a human centered design (HCI) approach with an emphasis on pervasive usability with representative users ... will help ensure that the digital environment is high on utility and ease-of-use." ${ }^{7}$

The International Organization for Standardization (ISO) formally defines usability as "the extent to which the product can be used by specified users to achieve specified goals with effectiveness, efficiency and satisfaction in a specified context of use." ${ }^{8}$ Analyses of the usability of virtual reference services must reach beyond the actual interface design of the tools. Mu et al. found "...there is no significant difference in users' opinions of a VRS [virtual reference service] and their willingness to use it that is caused by the design of the interface, provided ... users are aware of its existence and the link is clearly labeled with its function..."

Looking beyond the interface design of virtual reference tools and ensuring awareness of services, usability evaluations must consider what factors make virtual services effective, efficient, and satisfying. Several studies have found that the popularity and usability of virtual reference services may be dependent upon the type of question with which a patron presents. ${ }^{10}$ Other factors that may play a role in perceptions of usability may include the type of user, age, and gender of library patrons. ${ }^{11}$
A frequent oversight in the development of highly usable digital information environments (including virtual reference services) is this:

...designers frequently develop digital information spaces utilizing their own paradigms - what they deem to be important, organized in a fashion that makes the most sense to them-in absentia of the people that will actually be using it. This disconnect creates a gap between the designer and the user. ${ }^{12}$

While it is ideal to engage representative users as design partners from the very beginning of a project, many libraries bypass this vital step. A key element of application and implementation of a usable digital information environment is to continuously improve, refine, and collect representative feedback. ${ }^{13}$ Therefore, usability of virtual reference services can continue to be improved upon, even if already developed and implemented.

Understanding how the usability of virtual reference mediums affects a library patron's information-seeking experiences, preferences, and overall success will allow libraries to design and improve upon virtual reference services with greater precision, effectiveness, and efficiency. Usability must be a developmental keystone of a successful library experience; for, if users cannot access information easily, there is little point in expending the time, effort, and expense it takes to provide digital reference. ${ }^{14}$

The authors published an article examining the usability of virtual user services from the perspectives of university faculty, staff, students, and librarians..$^{15}$ A central limitation of this study was self-reporting from participants, many of whom had never used the virtual reference services they were rating. This study reflects the results of a more traditional usability evaluation with an emphasis on user testing, direct interaction with the services being tested, and the collection of specific metrics 
and data points representing an industry standard operational definition composed of specific measures for how a user views a service's effectiveness, efficiency, and satisfaction. Are particular virtual reference services more usable than others? Are there factors that make particular reference services more usable than others?

Whereas previous studies have examined usability from an opinion and largely nonempirical (without usability testing with actual users) perspective, this study seeks to answer these questions empirically by examining the usability of five virtual reference services (e-mail, telephone, online chat, text messaging reference, and Skype videoconferencing) offered in two doctoral-granting institutions in the southeastern United States through the perspectives and usability results of undergraduate and graduate students who evaluated each of the services.

\section{Literature Review}

When considering the usability of digital information environments, one must look closely at factors of effectiveness, efficiency, and satisfaction. ${ }^{16}$ While many studies have examined various aspects of the usability of e-mail and chat reference services, literature regarding the overall usability of the suite of virtual reference media offered by many libraries today (including e-mail, telephone, online chat, text messaging, and videoconferencing) is sparse. It does not reflect the more traditional usability practice of conducting formal usability tests involving users attempting to complete major tasks. Such formal testing allows more specific feedback through quantitative and qualitative test data; rather than relying solely on participant self-report opinions, it is based on their explicit ability to actually use a service or system.

\section{Do Characteristics of Reference Mediums Affect the Usability of Virtual Reference Services?}

Many studies have indicated that users value virtual reference services for their effectiveness, quality, convenience, speed, efficiency, and immediacy with which answers were received. ${ }^{17}$ However, differing characteristics of particular reference media may affect the overall usability, satisfaction with, and preferences for using individual virtual reference media. In a recent survey study and factor analysis of 936 university library users and their virtual reference preferences (e-mail, telephone, online chat, text messaging, and videoconferencing), Chow and Croxton found that, across all study respondents, e-mail was the most preferred (56.6\%) virtual reference medium over all other choices. ${ }^{18}$ In this same study, the most frequently cited reasons for e-mail preference were convenience, familiarity, ease of use, and a written record that was both precise and in depth. However, in a separate study using semistructured interviews with undergraduates, graduate students, and faculty members, Connaway, Radford, and Dickey found that, while the majority of respondents indicated that subject expertise was very important to them, only 42 percent would be willing to wait for that expertise, as is often required when using e-mail. ${ }^{19}$

Chow and Croxton further noted library patrons choose online chat, telephone, and text messaging reference services for their speed and quickness of response first, ease of use second, followed by multitasking (for using online chat). Texting and videoconferencing reference services received consistently low preference scores throughout this same study. ${ }^{20}$ Similarly, additional studies have found that individuals choose virtual reference services (such as online chat) for convenience, immediacy, efficiency, remote access, price, availability 24/7/365, anonymity, effectiveness, and quality. ${ }^{21}$

While e-mail, online chat, and telephone reference services are commonplace in libraries today, text and video reference are beginning to emerge as virtual reference media in academic libraries. However, little data currently exist in the literature regarding either 
the usage or usability of these services. Current research suggests usage of these emerging reference media is limited. In a review of digital reference activity for two semesters at Southeastern Louisiana University, Hill, Hill, and Sherman found text messaging constituted only a small portion of digital reference activity. Of 1,447 requests for information via digital reference, 66 percent $(n=954)$ were via chat, 28 percent $(n=410)$ were via email, and 6 percent $(n=83)$ were via text messaging. ${ }^{22}$ The researchers postulated, "With more convenient reference options available such as e-mail and 24/7 chat, patrons may choose these more robust forms of communication that are better suited for college level research questions." ${ }^{23}$ Research further suggests that online videoconferencing services may not be as usable as other forms of virtual reference. At Ohio University Libraries, Booth found, "The near impossibility of maintaining eye contact via a video chat interface is ...disconcerting and somewhat reduces one's ability to engage in an effective, traditional face-to-face reference interview." 24

Despite the generally positive findings regarding the usability of virtual reference services, other studies have brought to light negative factors that can affect the overall usability of virtual reference services. Dee and Allen suggested that problems accessing digital reference services and difficulty using it were two major barriers. ${ }^{25}$ Thomsett-Scott found that students dislike having to wait for responses from e-mail and chat. ${ }^{26}$

These findings may be explained, in part, by the concept of "strategic satisficing," introduced by Warwick et al., who noted that their subjects "used the expertise that they had ... gained in information seeking to create time-saving strategies to complete coursework with minimum effort." ${ }^{27}$ In this study, the researchers noted their subjects chose both sources and strategies within a well-known comfort zone in information seeking. These findings suggest that convenience may play a role in judging the usability of a reference medium.

This current study sought to determine which virtual reference medium is considered to be the most usable for library patrons.

\section{Does Type of Question Play a Role in the Usability of Virtual Reference Services?}

Several studies have been conducted that examine the types of questions users bring to virtual reference service and the suitability of particular virtual reference media for different types of questions. A general perception is that online chat reference is suitable mostly for simple factual and directional but not reference questions. ${ }^{28}$

Other researchers believe chat reference is capable of going beyond basic ready reference questions. ${ }^{29}$ Ward reported that 78 percent of chat reference transactions in an academic library showed some indication of bibliographic instruction or question negotiation, which typically occurs in subject-based research questions. ${ }^{30}$ In a review of survey data for 415 virtual reference transactions (such as online chat), Kwon found user satisfaction was the highest in subject-based research questions, while simple factual questions were the second highest, followed by local library information, circulation-related questions, and resource access questions. ${ }^{31}$

Bringing e-mail into the conversation, Lee found many similarities among the questions asked using e-mail and chat. ${ }^{32}$ Both chat and e-mail virtual reference received approximately the same proportion of questions about finding known items, research, and reference. E-mail received a small number of questions about referencing and citing, while chat received none of these questions.

According to the findings of Hill et al., text messaging reference is a unique virtual reference service well suited for short answer questions. They noted,

Most of the questions [via text messaging] have been of the short- 
answer variety.... However, the service also prompted short-answer reference questions ... that are atypical of reference questions received via phone, email, and chat. ${ }^{33}$

Chow and Croxton found the preference for using both text messaging and Skype videoconferencing to be very low. ${ }^{34}$ Though studies have shown the use of text messaging reference to be low, current trends reported by the Cellular Telecommunications Industry Association (CTIA) suggest text messaging reference may soon become a more prevalent medium, regardless of type of question. Between June 2007 and June 2008, CTIA reported a 160 percent increase in the number of text messages sent (from 28.8 billion to 75 billion). ${ }^{35}$

At this time there are no concrete data as to whether online videoconferencing is perceived to be more usable for either a quick, factual question or a researchrelated question. In a pilot study using Skype reference in an academic library, Booth noted, "overall trends confirmed our hypothesis that ... [Skype] ... would serve as a source for basic information rather than an in-depth point." 36 The limited research currently available about preferences for and/or usability of providing online videoconferencing services in libraries suggests users are simply not yet ready to use these services on a regular basis, regardless of the type of question with which they present. ${ }^{37}$

\section{Does Age or Patron Status Play a Role in the Perceived Usability of Virtual Reference Services?}

The type of patron may also play a role in perceptions of usability of virtual reference media. In a survey study of 345 chat users, Ward found that undergraduates saw the "chat" service as being applicable for most situations, while graduate students recommended the service noticeably more for ready reference questions. ${ }^{38}$

In their study of 936 university faculty, staff, and students, Chow and Croxton noted that, based on university status, age, gender, and race, specific users have particular reference service preferences based on type of question. They found this:

Faculty, staff, and graduate students ranked telephone for factual questions at significantly higher levels than undergraduate students. Faculty and staff prefer using e-mail for factual questions at significantly higher levels than both undergraduate and graduate students while students have a significantly higher preference for using text messaging.... All user groups rated online chat relatively high for seeking help with a factual question.... For research questions ...faculty, staff, and graduate students preferred e-mail at statistically higher levels than undergraduates, while undergraduate students preferred online chat at significantly higher levels than faculty and staff. ${ }^{39}$

If user preferences for particular reference services are an indicator of the actual usability of these services, one may expect the usability ratings to mirror that which is preferred. The findings of Chow and Croxton suggest users select their virtual reference medium according to the type of question they have. Role and age also appear to be influencing factors in determining reference preferences. ${ }^{40}$

Regardless of type of question, age, or role of the patron, information seeking appears to follow the Principle of Least Effort. Poole noted this principle to be the prominent result in a review of a dozen information-seeking studies. ${ }^{41}$ Overall, Poole found that information seekers attempt to minimize the overall work associated with something both now and in the future. Rubin further explains that people will seek the most convenient source available to meet their information needs. In a focus group study of 33 university faculty, undergraduates, 
and graduate students, Young and Von Seggern found that when considering criteria for information seeking, concern for time was brought up most often. ${ }^{42}$ Study participants would often accept inappropriate information or information of lower quality if finding it took less time. Therefore, the findings of Poole and Young and Von Seggern suggest library virtual reference services patrons may choose the reference medium that requires the least effort, that which is convenient, quick, and easy to use.

This study attempts to determine the overall usability of the suite of virtual reference media offered by many libraries today. The study further examines the factors that make particular virtual reference media more usable than others. Within this study, the type of question and role of the user and how they are related to usability ratings will be explored. Therefore, the purpose of the study is to seek answers to three research questions:

RQ1: Which virtual reference medium is most usable?

RQ2: Does the type of question play a factor in the usability of virtual reference media?

RQ3: Do perceptions of usability for virtual reference media differ depending on the role of the patron?

\section{Method}

To assess the usability of library virtual references services, this study used a mixed method quantitative and qualitative design to conduct a usability evaluation that analyzed and compared patrons' perceptions of usability of five virtual reference support services (e-mail, telephone, instant messaging [online chat], text messaging, and Skype videoconferencing) offered at two separate midsized public university libraries in the Southeast, each with a student population of approximately 18,500 . The study was conducted over five months in the spring of 2011.

\section{Participants}

A randomly selected group of under- graduates $(n=13)$ and graduate students $(n=18)$ participated in this study. Though 31 individuals participated in the study, there were occasions where fewer individuals responded to particular survey questions. Of the study participants, 74.2 percent were female and 25.8 percent were male. Age range was primarily concentrated under age 34, with the following breakdown: 48.3 percent under 24, 37.9 percent ages 25-34, 10.3 percent ages 35-44, and 3.4 percent ages 55-64. In terms of prior experience with the technologies used in the study, participants were experienced with e-mail, chat, and telephone, respectively, moderately experienced with text messaging, and inexperienced with using Skype.

\section{Materials, Instrumentation, and Data Analysis}

To properly conduct a usability evaluation for each of the virtual reference services, each study participant was emailed a set of detailed instructions that included 10 different questions - five quick, factual questions and five procedural or research-based questions that required a more detailed response by the librarian (see Appendix A for sample instructions). The questions assigned to study participants were of similar subject matter and depth. The actual questions, however, differed throughout the study to control for familiarity with the questions received on the part of the reference librarian (see Appendix B for a list of questions). Participants were assigned a particular university library (University A or University B) to which to direct their preassigned questions. Fifteen participants asked questions virtually at University A, while 16 participants asked virtual reference questions at University B. Questions were asked using the five virtual reference services (e-mail, telephone, online chat, text messaging, and online videoconferencing) as illustrated in table 1. An exception was that University B did not offer online videoconferencing. 


\begin{tabular}{|c|c|c|c|c|c|c|c|c|c|c|c|c|}
\hline & Participant & $\begin{array}{r}\text { TAB } \\
\text { requency } C\end{array}$ & $\begin{array}{l}\text { E } 1 \\
\text { unt }\end{array}$ & $5 \times 1$ & ype & of $C$ & Ques & & & & & \\
\hline University & Student Type & Participants & & fere & nce & Servi & $\begin{array}{l}\text { ce a } \\
\text { Que }\end{array}$ & $\begin{array}{l}\text { d Ty } \\
\text { tion }\end{array}$ & pe $\&$ & $\mathrm{Nu}$ & mbe & \\
\hline & & & E-n & nail & Ph & one & & & & $\mathrm{xt}$ & Sk & pe* \\
\hline & & & 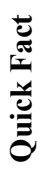 & 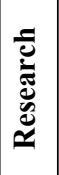 & 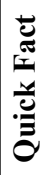 & 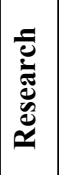 & 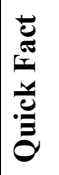 & 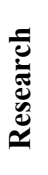 & 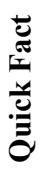 & 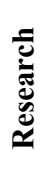 & 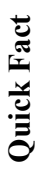 & 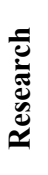 \\
\hline University A & Grad Student & 9 & 9 & 8 & 9 & 8 & 9 & 9 & 9 & 6 & 8 & 7 \\
\hline & Undergraduate & 6 & 6 & 6 & 6 & 6 & 6 & 6 & 6 & 6 & 5 & 5 \\
\hline University B* & Grad Student & 9 & 9 & 8 & 9 & 9 & 9 & 9 & 8 & 8 & 0 & 0 \\
\hline & Undergraduate & 7 & 7 & 7 & 7 & 7 & 6 & 6 & 6 & 5 & 0 & 0 \\
\hline Total & & 31 & 31 & 29 & 31 & 30 & 30 & 30 & 29 & 25 & 13 & 12 \\
\hline
\end{tabular}

Subjects completed online surveys of their experiences - rating measures of usability and satisfaction after evaluating each virtual reference medium (see Appendices C-G for survey instruments). Preferences for reference formats were ranked at the completion of the study (see Appendix H). Data regarding study participants' prior experience with virtual reference media or tools were gathered at the beginning of participation in the study.

The instructions and survey instruments were pilot tested with graduate students for preliminary face and construct validity, refined accordingly, and then administered via e-mail to study participants.

\section{Virtual Reference Services Tested}

Five virtual reference mediums were tested in this study. Consistent across each of the media, study participants were instructed to ask the first, preassigned quick, factual question, wait four hours, and then ask the second, preassigned procedural, research-based question. Once replies to both questions were received, study participants were instructed to complete online surveys of their experiences after each medium was tested. E-mail reference was used by directing study participants (through a link in their e-mailed instructions) to a university library's Ask Us! page. Subjects were then instructed to move on to Telephone reference. They were given tollfree phone numbers to use to call their assigned library's reference desk. At the completion of telephone reference evaluation, participants were then instructed to contact the Online Chat reference services and ask both factual and procedural research-based questions. Participants were given a link in their instruction set that directed them to the online chat window. Study participants then were instructed to contact the library using text messaging reference via their cell phones/mobile devices. They were given a specific number to contact via text, along with a particular number and/or word to initiate their reference inquiries. Finally, study participants contacting University A were instructed to contact the Reference Department via Skype videoconferencing and ask their two assigned questions, waiting at least four hours between each inquiry. (University B does not offer videoconferencing reference at this time.) Participants were given specific instructions about how to contact the library using a given Skype username. Participants needed to have a computer with the free 


\begin{tabular}{|c|c|c|c|c|c|c|c|c|c|c|}
\hline \multicolumn{11}{|c|}{$\begin{array}{c}\text { TABLE } 2 \\
\text { Undergraduate and Graduate Reference Service Preferences }\end{array}$} \\
\hline \multicolumn{11}{|c|}{ Undergraduate and Graduate Student Usability Ratings } \\
\hline & \multicolumn{2}{|c|}{ E-mail } & \multicolumn{2}{|c|}{ Telephone } & \multicolumn{2}{|c|}{ Chat } & \multicolumn{2}{|c|}{ Skype } & \multicolumn{2}{|c|}{ Text } \\
\hline & $\mathbf{U G}$ & $\mathbf{G}$ & UG & $\mathbf{G}$ & UG & $\mathbf{G}$ & UG & $\mathbf{G}$ & $\mathbf{U G}$ & G \\
\hline Effectiveness & 8.4 & 8.1 & 8.9 & 8.5 & 9.5 & 9.7 & 5.8 & 6.4 & 5.8 & 6.3 \\
\hline Task Completion & 8.9 & 7.9 & 9.0 & 8.6 & 9.5 & 9.5 & 5.8 & 6.6 & 6.1 & 6.3 \\
\hline Quality of Output & 7.8 & 8.2 & 8.8 & 8.4 & 9.5 & 9.8 & 5.8 & 6.2 & 5.5 & 6.3 \\
\hline Efficiency & 8.7 & 8.0 & 8.9 & 8.5 & 9.2 & 9.4 & 5.8 & 5.0 & 6.5 & 6.3 \\
\hline Deviations & 9.3 & 8.3 & 9.2 & 9.0 & 9.5 & 9.4 & 5.4 & 4.9 & 6.5 & 6.4 \\
\hline Error Rate & 9.1 & 8.6 & 9.2 & 9.0 & 9.5 & 9.5 & 5.6 & 5.4 & 6.9 & 6.3 \\
\hline Time on Task & 7.3 & 7.3 & 8.5 & 7.7 & 8.9 & 9.6 & 6.4 & 4.7 & 5.7 & 6.2 \\
\hline Mental Effort & 9.1 & 7.9 & 8.7 & 8.4 & 9.1 & 9.4 & 5.8 & 4.9 & 7.0 & 6.2 \\
\hline Satisfaction & 8.4 & 7.8 & 9.0 & 8.5 & 9.4 & 9.7 & 5.8 & 5.6 & 6.4 & 6.4 \\
\hline Usability (Grand Mean) & 8.5 & 8.0 & 8.9 & 8.5 & 9.3 & 9.5 & 5.8 & 5.5 & 6.3 & 6.3 \\
\hline
\end{tabular}

Skype software downloaded as well as a web camera. After participants completed this portion of the study, they completed online surveys of their experiences with this reference medium.

\section{Results}

"...chat has the speed and efficiency of phone usage and the in-depth effectiveness of email" (research participant)

\section{Instant Messenger Chat the Clear Choice}

The results found a perfect relationship between participant satisfaction and their usability ratings for each refer-

\begin{tabular}{|c|c|c|}
\hline \multicolumn{3}{|c|}{$\begin{array}{c}\text { TABLE } 3 \\
\text { Combined Undergraduate and } \\
\text { Graduate Ratings for Reference } \\
\text { Service Preferences }\end{array}$} \\
\hline $\begin{array}{l}\text { Reference } \\
\text { Medium }\end{array}$ & $\begin{array}{l}\text { Research } \\
\text { Question }\end{array}$ & $\begin{array}{c}\text { Factual } \\
\text { Question }\end{array}$ \\
\hline Chat & 9.1 & 8.9 \\
\hline Telephone & 9 & 7.5 \\
\hline E-mail & 7.5 & 7.1 \\
\hline Text & 5.9 & 5.8 \\
\hline Skype & 5.8 & 6.3 \\
\hline
\end{tabular}

ence medium tested during the study. Undergraduate and graduate students were most satisfied with chat reference, for both research and factual questions, followed by telephone, e-mail, text, and Skype, respectively. See table 2.

Table 3 shows the combined cumulative scores of both graduate and undergraduate students.

Chat was also rated the highest across all usability factors by participants: more effective (9.6 out of 10), efficient (9.4), and satisfying to use (9.6) than any other reference service. Participant usability ratings for the remaining four reference services-telephone, e-mail, text, and Skype-also exactly paralleled participant satisfaction. See figure 1.

Chat was rated the most usable service because it scored the highest for all reference services across all seven usability factors for both research and factual questions. One-way ANOVA, a statistical test used to compare mean scores within and between groups, showed that the usability ratings for chat across participants were statistically the same for six of seven usability factors, which suggests consistently high ratings for chat across participants. Overall, chat had statistically significant higher usability 


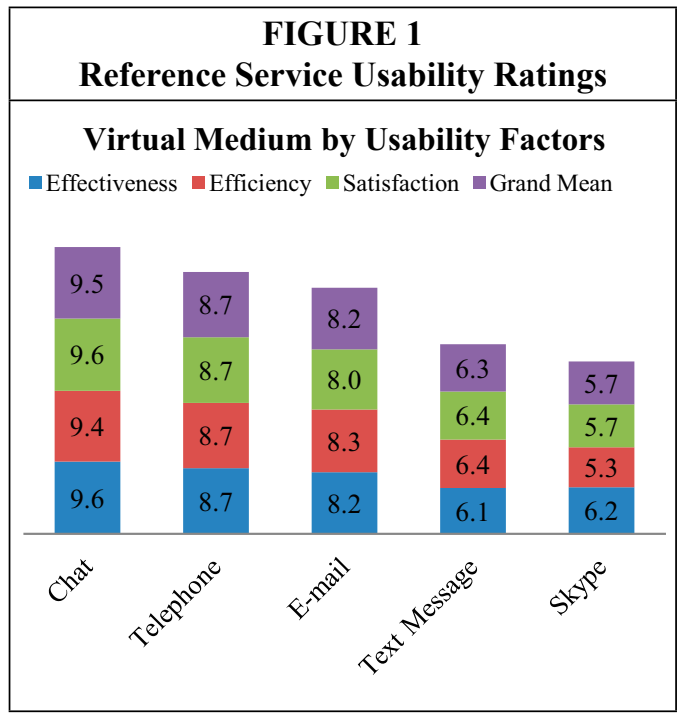

ratings across factors in comparison to other media with its grand mean (mean of means for all factors) being statistically significantly higher than e-mail and Skype. See table 2.

\section{Face-to-face Versus Virtual Reference}

When participants were asked to select only one reference medium including face-to-face, participants still preferred chat reference more frequently for both research (53\%) and factual (60\%) reference questions than all other reference options combined. See tables 5 and 6.
Online chat and telephone combined represented the preferences of 73 percent of the study's participants for seeking help with a basic factual question. See table 6 .

\section{Time a Factor}

Four of the five reference services-chat, telephone, text, and Skype-represent potentially quick responses to participants' questions. For factual questions, chat had the quickest response time, with 96 percent of all transactions taking less than five minutes and with 23 percent taking less than a minute. The second-highest rated reference service was telephone, with 90 percent of all transactions taking less than five minutes and with 42 percent taking less than a minute to complete. Both chat and telephone were rated the first and second most preferred, respectively.

In contrast, only 52 percent of text message and 67 percent of Skype transactions were completed within five minutes. For e-mail, more of an asynchronous mode of communication, only 52 percent of transactions were resolved within one hour, and 39 percent took over 12 hours to resolve.

The pattern was similar for research questions. Chat transactions had 100

\begin{tabular}{|c|c|c|c|c|c|}
\hline \multicolumn{6}{|c|}{$\begin{array}{r}\text { TABLE } 4 \\
\text { Reference Service by Individua }\end{array}$} \\
\hline Factor & Chat & Tel. & E-mail & Text & Skype \\
\hline Task Completion & $9.5 *$ & $8.8^{* *}$ & $8.3^{* * *}$ & $6.2 *$ & $6.3^{*}$ \\
\hline Quality of Output & 9.7 & $8.5^{*}$ & $8.1 * *$ & $6.0^{*}$ & 6.1 \\
\hline Deviations & 9.4* & $9.1 * *$ & $8.7 * * * * *$ & $6.5^{*}$ & 5.1 \\
\hline Errors & $9.5 *$ & $9.1 *, * * *$ & $8.8^{*}, * * *$ & $6.5^{*}$ & $5.5^{*}$ \\
\hline Time on Task & 9.3* & 8.0 & $7.3 * *$ & 6.0 & $5.3 *$ \\
\hline Mental Effort & 9.3* & 8.5 & $8.4 *$ & 6.5 & $5.2 *$ \\
\hline Satisfaction & $9.6 *$ & 8.7 & $8.0 * * *$ & 6.4 & 5.7 \\
\hline Grand Mean & $9.5 *$ & 8.7 & $8.2 * *$ & 6.3 & $5.7 * *$ \\
\hline \multicolumn{6}{|c|}{$\begin{array}{l}* \text { Homogeneity of Variance is significant at the } p<.05 \text { level. } \\
* * \text { Statistically significant at the } p<.05 \text { level. } \\
* * * \text { Statistically significant at the } p<.01 \text { level. }\end{array}$} \\
\hline
\end{tabular}




\begin{tabular}{|c|c|c|}
\hline \multicolumn{3}{|c|}{$\begin{array}{c}\text { TABLE } 5 \\
\text { Reference Service Preferences } \\
\text { for Research Questions }\end{array}$} \\
\hline Medium & f & $\%$ \\
\hline Online Chat Reference & 16 & $53.3 \%$ \\
\hline Face-to-Face Consultation & 8 & $26.7 \%$ \\
\hline E-mail Reference & 5 & $16.7 \%$ \\
\hline Telephone Consultation & 1 & $3.3 \%$ \\
\hline Skype Video Reference & 0 & $0.0 \%$ \\
\hline Text & 0 & $0.0 \%$ \\
\hline
\end{tabular}

percent resolved and telephone resolved 97 percent of all transactions within 15 minutes or less. Skype had 15 percent and text had 31 percent of their transactions take longer than one hour. For e-mail, 48 percent of all transactions took longer than two hours and 30 percent took 12 hours or longer.

\section{Chat Favored Independently of All Factors}

Analysis of various factors found no significant differences for gender, age, race, library, or prior experience. This suggests that the majority of participants consistently rated chat and the four other media independent of other factors.

\section{Discussion}

The results of our study support our previous study, which found undergraduate students preferred online chat over all other reference services. ${ }^{43}$ One limitation of that study was the majority of respondents to our survey had not actually used the reference services. This study represents one of the first usability evaluations, which had participants specifically test each reference service by using each of them to answer a set of tasks. Participants tested each service for both research and factual questions and rated each across seven established usability factors. ${ }^{44}$ The results help operationally define participant preferences based on usability ratings emphasizing effectiveness, efficiency, and satisfaction.
Online chat was rated highest in effectiveness, efficiency, and satisfaction. One reason for this was because of how fast the transactions were in comparison to all other services. In addition, participants noted other prominent factors such as real-time interaction, the ability to multitask while chatting, the convenience of "already being on the computer," and the visual and archival aspects of text-based chat that also allows for the sharing of links. As one participant noted:

Chat was more user friendly than the telephone. I think that seeing the response in a written form helps me to crystallize my understanding of the answer. I also liked the fact that the librarian could easily send me links via the chat; it would be more difficult to do so over the telephone. I also think that the chat was a lot more to the point, without being curt; on the telephone you actually have to converse with the other person which may not be ideal if a quick answer is needed.

Telephone was the next most preferred reference medium and, similar to chat, had an extremely fast transaction time for participants. In fact, an immediate response was the primary factor mentioned by participants for why they liked using the telephone. The other prominent factor was the real-time interaction. As one

\begin{tabular}{|l|c|c|}
\hline \multicolumn{3}{|c|}{ TABLE 6 } \\
Reference Service Preferences for \\
Factual Questions \\
\hline Medium & f & \% \\
\hline Online Chat Reference & 18 & $60.0 \%$ \\
\hline Telephone Consultation & 4 & $13.3 \%$ \\
\hline Text-a-Librarian Reference & 3 & $10.0 \%$ \\
\hline Face-to-Face Consultation & 2 & $6.7 \%$ \\
\hline Other & 2 & $6.7 \%$ \\
\hline E-mail Reference & 1 & $3.3 \%$ \\
\hline Skype Video Reference & 0 & $0.0 \%$ \\
\hline
\end{tabular}


participant put it, "I like the telephone for when I need information quickly and right then." Another noted, "Through telephone you can again ask questions or recheck something with the person and would receive more accurate response in a timely manner." One negative for telephone service is that it may cost students money by using limited cell phone minutes.

E-mail was the third-rated reference service. Unlike the other four services, the majority of e-mail transactions took over 12 hours to complete. While it is much slower compared to the other services, strong points include the ability to ask a detailed question and receive a similarly detailed response with web links. In addition, it serves as a written record that can be referred back to anytime. One participant noted, "[E-mail] communication allows for the responder to provided [sic] detailed information along with links, examples, and attachments."

Text messaging was rated much lower than expected given the prevalence in which students use text messaging for social communication. Participants noted that one of the reasons text was rated so low was that, although it is very similar to online chat, they had to remember a phone number and use a cell phone as opposed to just opening a web browser and engaging in an online chat from their computer. As one participant noted, "I liked chat better than text messaging because it was all on the computer. The chat told me when the person was responding so I liked that. I wasn't just waiting around." Another issue was the quality of support for text messaging reference services as several participants noted they never received a response at all and gave up.

Skype was the lowest-rated reference service. Analysis of participant comments suggests that this low rating was due to a host of problems. First was technical in nature-some could not get the software to work properly, some did not have a functional webcam, and others had slow connections. Second, while some lauded the ability to see and hear the reference librarian, others did not feel that visual cues added anything to the process and at times made them feel uncomfortable. One participant noted the differences between chat and Skype: "Chat was very fast and simple to use-I didn't have to download a new program onto my computer to get answers. Also, being able to see and hear the person made me feel a little weird because I don't usually communicate with people via video chat."

\section{High Usability, High Satisfaction}

The International Organization for Standardization defined usability as a person's ability to use a product or service with maximum effectiveness, efficiency, and satisfaction. Using this framework, our study found a perfect positive relationship between user preferences and how they rated each reference service across usability factors - the higher the usability, the more highly rated the reference service was. In other words, the higher the participant's return-on-investment in terms of time and mental effort, the more highly rated the service. This supports the concept from Warwick et al. of strategic satisficing, where students choose the information-seeking paths that are most comfortable and convenient for them. ${ }^{45}$

The results of the study suggest that each of its three research questions can be answered: online chat was found to be the most usable and participant preference was independent of all other factors examined including type of question, university service tested, gender, race, academic status, or age.

\section{Study Limitations}

The study had four primary limitations. First, the study conducted a usability evaluation instead of a traditional usability test with participants in a lab setting; outside of this controlled testing environment, the study relied on the selfreports of students under the assumption that they actually completed all tasks and 
completed each of the usability surveys in a valid, authentic manner. Second, a low sample size of only 31 student participants evaluating two university reference services limits the study's internal and external validity and overall generalizability. The third major limitation was that Skype reference services were not offered at both reference departments, and therefore only half of the participants were able to evaluate and test this service. The last primary limitation had to do with the quality of scenarios used to test the reference services. Feedback from one library's reference service staff was that the redundant questions being asked allowed them to recognize participants in the study and may have slightly influenced the quality of responses they received.

\section{Conclusion}

The study's implications center on the fact that it represents one of the first formal usability evaluations of library virtual reference services using a usability framework. Five types of virtual reference services were examined at two different university reference departments and the results clearly suggest that participant satisfaction and preferences were guided by time of response, convenience, effectiveness, and efficiency.

Online chat was clearly preferred by the majority of participants and rated the highest for time of response and across all seven usability factors on a statistically significant basis-task completion, quality of output, deviations, errors, timeon-task, mental effort, and overall satisfaction. These findings support Poole's Principle of Least Effort where information seekers want access to information with the least amount of effort possible. ${ }^{46}$

Online chat appears to combine the strengths of other reference services into one service: the immediacy of response and real-time interaction of telephone, the convenience, written record and content sharing of e-mail, and the instant messaging of text-messaging and Skype. The study's results suggest that, with the increased proliferation of wireless technologies such as smartphones and tablets, instant messaging chat may continue to grow in popularity as the younger population entering college will be even more familiar and comfortable with this technology.

Given the rapid changes brought on through current and emerging technologies, there is a need for more agile methods of measuring usability in the field. Making use of the study's instruments and protocol, the study represents a process for how to conduct similar usability evaluations that have users complete a set of tasks so that they have actually "tested" the service before completing a scale about the overall effectiveness, efficiency, and satisfaction of their user experience. This provides organizations with both qualitative and quantitative data to ensure at a more precise level that services are indeed high in usability. Furthermore, the quantitative data can be analyzed statistically to see more clearly what specific factors of usability might represent opportunities for improvement.

Such usability evaluations, while less comprehensive and valid than traditional usability testing in controlled environments, may replace the use of the standard controlled usability test in terms of frequency and choice because it is much quicker, cost effective, and viable to conduct. This may lead to usability evaluations occurring more often. These will complement rather than completely replace controlled tests, which should still take place but less often and for only those who are prepared to do so with the appropriate time, participants, and hardware and software.

Future research involves seeking to replicate this study at other universities as well as to examine faculty and staff usability evaluations for the same virtual reference services, who have been found to prefer e-mail over chat. In addition, further examination of whether these findings can generalize to the virtual reference service preferences of public and special library patrons need to also be explored. 


\section{Appendix A.}

\section{A Comparison Study of Library Reference Services Revised Research Study Procedures}

The goal of the study is to compare the overall usability of four types of reference services - telephone, e-mail, online chat, and text messaging.

As a participant in our study you will ask two reference questions in each of these four formats to the library reference staff at the XXXXX University Library. After receiving a response to your questions in each format we want you to complete an online survey regarding your overall experience-include a detailed description of the general process you followed to seek and receive help, approximately how long the entire transaction took from start-to-finish, and your general thoughts and reactions to the experience. When possible, please try to ask your reference questions at different times throughout the day.

After you have sought and received help in all four mediums, please complete a final debriefing survey that will collect basic demographic information, assess each of the reference environments on major usability factors, and ask you to rank which of the mediums you preferred and why.

Note: The XXXXX Library Reference Desk is staffed during the following hours. For optimal results, we recommend you contact the library during the following hours:

\begin{tabular}{|c|c|}
\hline & \\
\hline Sunday & 1 p.m. -5 p.m. \\
\hline Mon.-Thu. & 9 a.m. -9 p.m. \\
\hline Friday & 9 a.m. -5 p.m. \\
\hline Saturday & 10 a.m. -5 p.m \\
\hline
\end{tabular}

Here is a step-by-step procedure you can follow to complete the study:

\section{Format 1: Email}

Note: Please keep track of how long it took from start-to-finish to have each question answered. Also, take notes of any thoughts, observations, or opinions you have so that you can share these with us at the end of the project.

1. Go to the XXXX Library Contact Us web page and complete the "Email a Question" form at: (hyperlink to university ask us email page). Under the drop down box for "Where would you like your question sent?" select XXXXX Library.)

2. Complete the form along with your email address and enter this first question in the form provided:

"What are the hours and phone number for the Writing Center on campus?"

3. If the answer was satisfactory, please repeat steps 1 and 2 but instead ask this second question:

"How do I cite a blog in APA format?"

4. Try out the response to make sure it is satisfactory.

5. When you feel the answer was satisfactory (if not, please ask a follow-up question via e-mail) please complete this evaluation form for receiving email assistance (link to online survey) on your experience. 


\section{Format 2: Telephone}

Note: Please keep track of how long it took from start-to-finish to have each question answered. Also, take notes of any thoughts, observations, or opinions you have so that you can share these with us at the end of the project.

Note: It is preferable if you complete your email questions/interactions before asking the following questions via telephone. If possible, please wait at least four hours from the time you have completed your email questions/interactions before asking the questions via telephone.

1. Call the XXXXX University Library Library Reference Desk at 1-800-XXX-XXXX and ask following question:

"I'm looking for the phone number and hours for the Student Recreation Center. Can you help?"

2. If the answer was satisfactory, please repeat step 1 but instead ask this second question:

"How do I cite a book that has three authors using APA format?"

3. Try out the response to make sure it is satisfactory

4. When you feel the answer was satisfactory (if not, please ask a follow up question via email) please complete this general evaluation form for the telephone format (hyperlink to online survey) on your experience.

\section{Format 3: Chat}

Note: Please keep track of how long it took from start to finish to have each question answered. Also, take notes of any thoughts, observations, or opinions you have so that you can share these with us at the end of the project.

Note: It is preferable if you complete your telephone questions/interactions before asking these same questions via online chat. If possible, please wait at least four hours from the time you have completed your telephone questions/interactions before asking the questions via chat.

1. Go to the XXXX University Library Contact Us Web page at (hyperlink to library contact us page)

2. Use the imbedded chat box provided on the left side of the page under Ask a Librarian.

3. Ask the following question:

"Can you help me find the phone and hours for the Financial Aid Office?"

Note: Please copy and save the full text of the response that you receive to your question here so that you can include it in the debriefing survey.

4. If the response was satisfactory, please repeat steps 1-3 but instead ask this second question.

"How do I cite a newspaper article from an online newspaper using APA format?" Note: Please copy and save the full text of the response that you receive to your question here so that you can include it in the debriefing survey.

5. Try out the response to make sure it is satisfactory.

6. When you feel the answer was satisfactory (if not, please ask a follow-up question via chat) please complete this general evaluation form on your experience with chat (hyperlink to online survey). 


\section{Format 4: Skype}

Note: Please keep track of how long it took from start to finish to have each question answered. Also, take notes of any thoughts, observations, or opinions you have so that you can share these with us at the end of the project.

Note: It is preferable if you complete your online chat questions/interactions before asking these same questions via Skype. If possible, please wait at least four hours from the time you have completed your online chat questions/interactions before asking the questions via Skype.

1. Open up Skype on your computer and please test to make sure both your audio and video are working before contacting the reference desk.

2. Once you are confident everything is working, please contact the Library Web reference desk through Skype by going to (hyperlink to Library Skype Desk) Ask the following question in the manner provided:

"I'm trying to find the hours and phone number for the Cashier's Office. Can you help?"

3. If the response was satisfactory, please repeat steps 1-3 but instead ask this second question.

"How do I cite an electronic book in APA format?"

4. Try out the response to make sure it is satisfactory.

5. When you feel the answer was satisfactory (if not, please ask a follow up question via Skype) please complete this general evaluation form on your experience using Skype (hyperlink to online survey).

\section{Format 5: Text Messaging}

Note: Please keep track of how long it took from start to finish to have each question answered. Also, take notes of any thoughts, observations, or opinions you have so that you can share these with us at the end of the project.

Note: It is preferable if you complete your Skype questions/interactions before asking these same questions via Text Messaging. If possible, please wait at least four hours from the time you have completed your Skype questions/interactions before asking the questions via Text Messaging.

1. Using your cell phone or mobile device, ask the following question by sending a text message to the Text-a-Librarian service. Send your question to (800) xxx-xxxx. "Can you help me figure out the hours and phone number for the Academic Success Program?"

2. If the response was satisfactory, please repeat step 1 but instead ask this second question.

"How do you cite an article from a magazine in APA format?"

3. Try out the response to make sure it is satisfactory.

4. When you feel the answer was satisfactory (if not, please ask a follow-up question via text), please complete this general evaluation form on your experience using Text-a-Librarian (hyperlink to online survey).

Note: The final question of this survey asks you to compare text messaging to Skype. In the comments field, please indicate that you did not evaluate Skype.

\section{Evaluation of Each Format}

1. Now that you have had the questions answered in each of the four formats, we want you to complete a final survey that assesses the general usability of each technology along with some general thoughts and observations. 
2. Only after you have had your questions answered satisfactorily in each of the four formats above please complete this final survey.

Notes:

- On the final survey form you will encounter a page relating to Skype video conferencing. You may either skip those questions or answer NA when appropriate.

- One the final page of the final survey, you will encounter some questions relating to Rating Your Preferences of Formats. Please go ahead and answer these questions (even though they include Skype as an option).

\begin{tabular}{|c|c|}
\hline \multicolumn{2}{|c|}{$\begin{array}{c}\text { APPENDIX B } \\
\text { Questions Used for this Study }\end{array}$} \\
\hline Quick, Factual Questions & Research/Procedural Reference Questions \\
\hline $\begin{array}{l}\text { Can you help me figure out the } \\
\text { hours and phone number for the } \\
\text { Student Success Center? } \\
\text { Can you help me find out who to } \\
\text { contact to get some information for } \\
\text { tutoring in math? } \\
\text { Can you help me find the address } \\
\text { for the International Students \& } \\
\text { Scholar Program? } \\
\text { Can you help me find the phone and } \\
\text { hours for the Financial Aid Office? } \\
\text { Can you help me find the street } \\
\text { address for the Family Research } \\
\text { Center? } \\
\text { Can you help me find the street } \\
\text { address for the Global Research } \\
\text { Institute? } \\
\text { Can you help me find the street ad- } \\
\text { dress for the parking office? } \\
\text { Can you tell me where the book- } \\
\text { store is on campus? } \\
\text { Can you tell me where the Writing } \\
\text { Center is located? } \\
\text { Do you know the dates we're off for } \\
\text { Winter Break? } \\
\text { Do you know the hours and phone } \\
\text { number for the Student Health } \\
\text { Center? } \\
\text { Do you know what day classes start } \\
\text { for the Summer Session? }\end{array}$ & $\begin{array}{l}\text { - Can you help me find some biographical } \\
\text { information on Cesar Ritz, the founder of } \\
\text { the Ritz hotels? I'm supposed to try to use a } \\
\text { database or find a book. } \\
\text { - Can you help me find some biographical } \\
\text { information on Conrad Hilton? I'm not sup- } \\
\text { posed to use Google. } \\
\text { - Can you help me find some biographical in- } \\
\text { formation on former first lady, Laura Bush? } \\
\text { I'm supposed to try to use something other } \\
\text { than Google. } \\
\text { Can you help me find some biographical } \\
\text { information on Julia Child. I'm supposed to } \\
\text { use a database or find a book. } \\
\text { - Can you show me how to cite a magazine } \\
\text { article using MLA format? } \\
\text { Can you tell me how to cite a book with two } \\
\text { authors using APA format?" } \\
\text { Can you tell me how to cite a book with two } \\
\text { authors using MLA format? } \\
\text { - Can you tell me how to cite a chapter from a } \\
\text { book using APA format? } \\
\text { - How can I find some biographical infor- } \\
\text { mation on Michael Jordan, the basketball } \\
\text { player, without using Google? } \\
\text { - How can I find some biographical informa- } \\
\text { tion on Ray Kroc, the founder of McDon- } \\
\text { ald's, without using Google? } \\
\text { catalog can I lian I log to online resources? } \\
\text { catalog so I see only books available in } \\
\text { ish come up? } \\
\text { canish? } \\
\text { - }\end{array}$ \\
\hline
\end{tabular}




\begin{tabular}{|c|c|}
\hline \multicolumn{2}{|c|}{$\begin{array}{c}\text { APPENDIX B } \\
\text { Questions Used for this Study }\end{array}$} \\
\hline Quick, Factual Questions & Research/Procedural Reference Questions \\
\hline 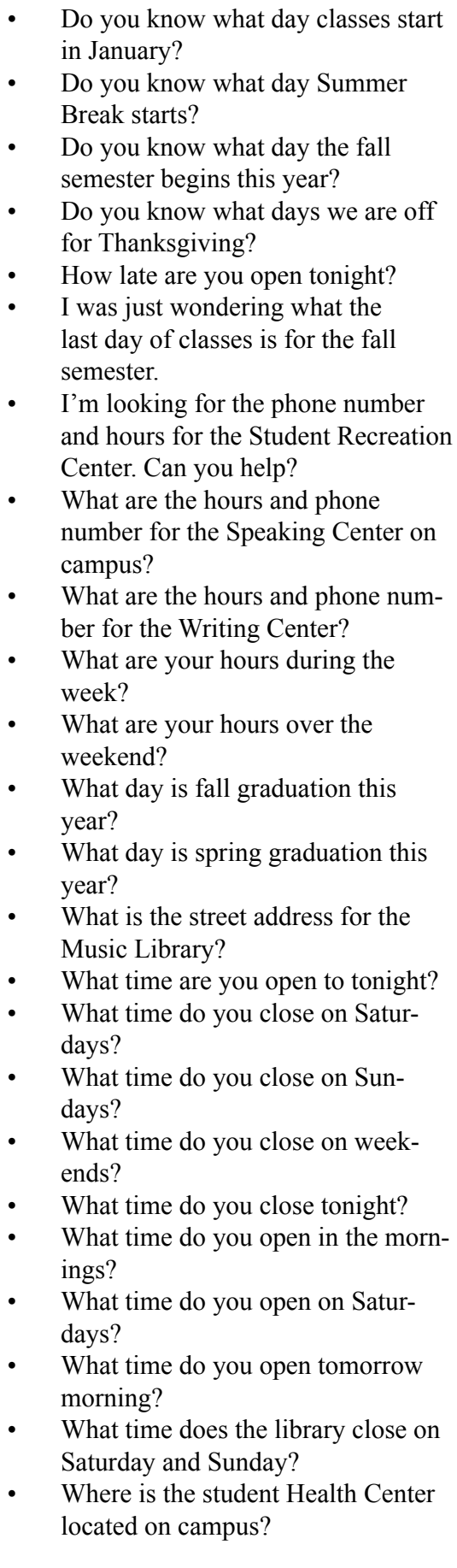 & 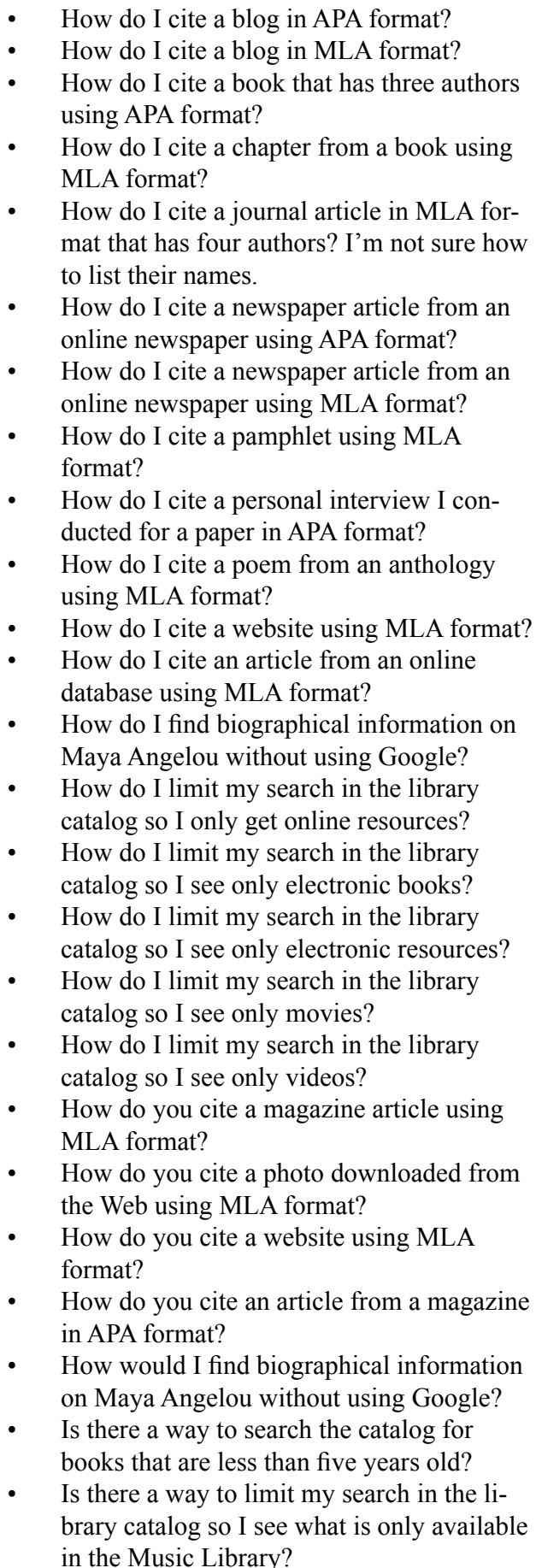 \\
\hline
\end{tabular}




\section{Appendix C. \\ E-mail Online Survey}

\section{E-mail Format}

Please give us your feedback on receiving assistance via e-mail by answering the following questions.

\section{*1. Your Name:}

2. To which university library did you direct your questions for this study?

University A

University B

*3. Please copy and paste the first question that you asked.

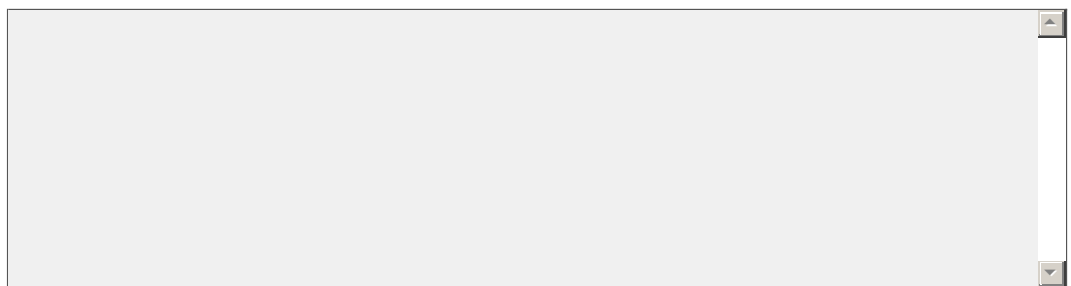

4. Please copy and paste the full text of your e-mail response to question 1 in the form below:

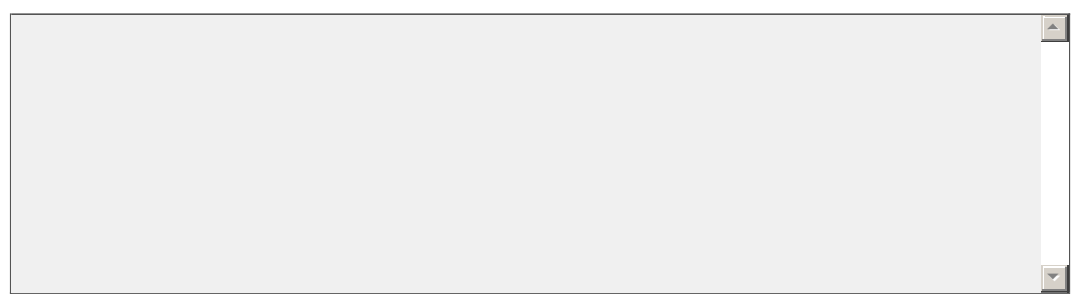

5. Approximately how long, from start to finish, did it take for your question to be answered?
Less than 1 hour
1-5 hours
6-10 hours
12-23 hours
1 day
2 days
3 or more days 


\section{Appendix C. \\ E-mail Online Survey}

\section{E-mail Format}

6. On a scale from 1-10 (1=lowest, 10=highest satsifaction), rate how satisfied you were with the overall experience in getting your first question answered.

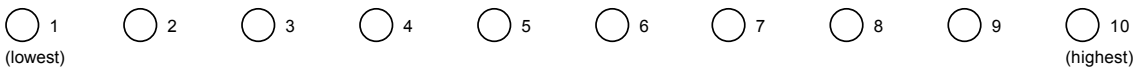

Please elaborate on why you rated as you did (quicker/slower response than expected; response was adequate; general comfort level in asking question, etc.):

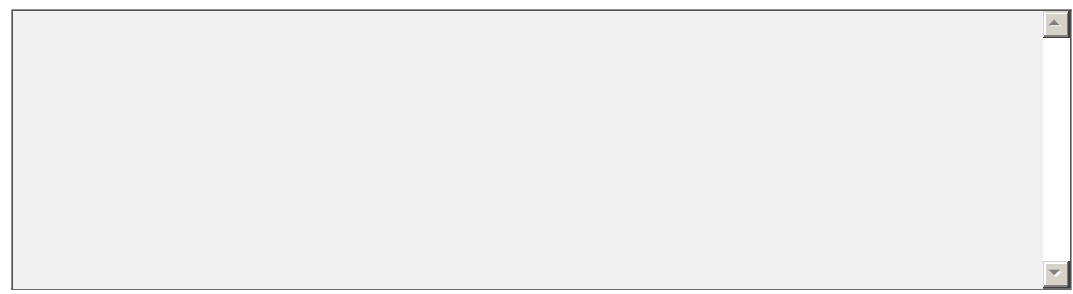

*7. Please copy and paste the second question that you asked.

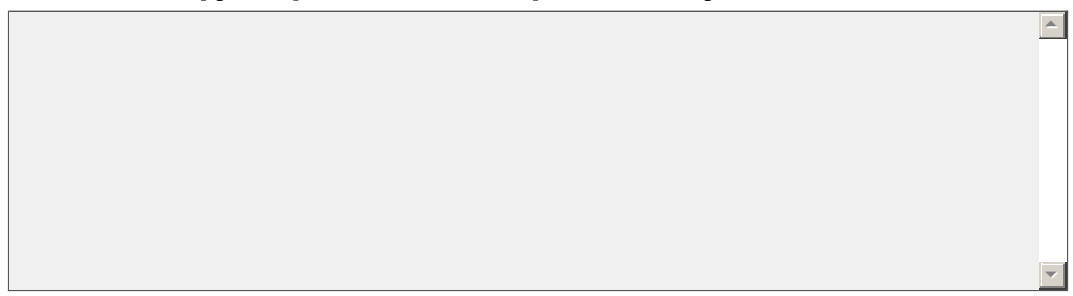

8. Please copy and paste the full text of your e-mail response to question $\mathbf{2}$ in the form below:

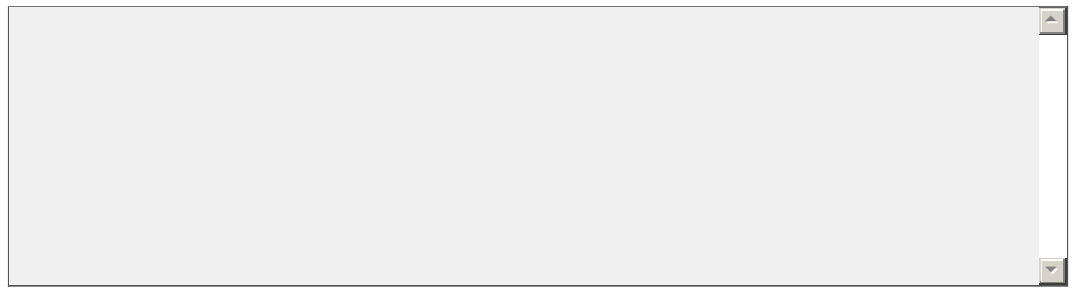




\section{Appendix C. \\ E-mail Online Survey}

\section{E-mail Format}

9. Approximately how long, from start to finish, did it take for your question to be answered?
Less than 1 hour
1-5 hours
6-10 hours
12-23 hours
1 day
2 days
3 or more days

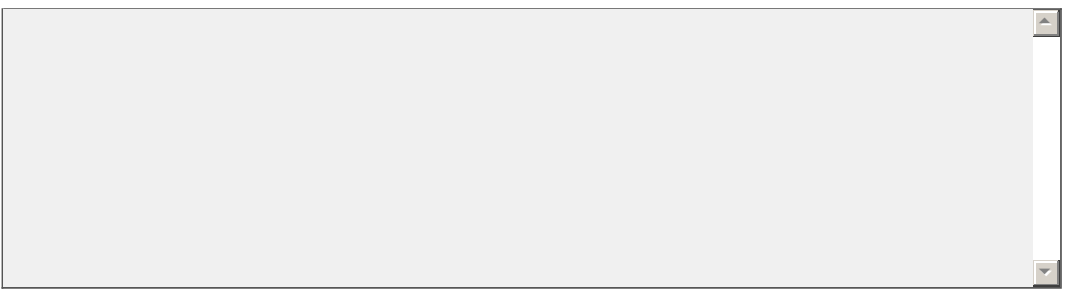

10. On a scale from 1-10 (1=lowest, 10=highest satsifaction), rate how satisfied you were with the overall experience in getting your second question answered.
$\bigcirc 1$
$\bigcirc 2$
${ }_{3}$
$\mathrm{O}_{4}$
${ }_{5}$
${ }_{6} \bigcirc 7$

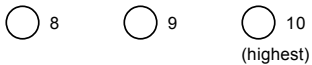

Please elaborate on why you rated as you did (quicker/slower response than expected; response was adequate; general comfort level in asking question, etc.):

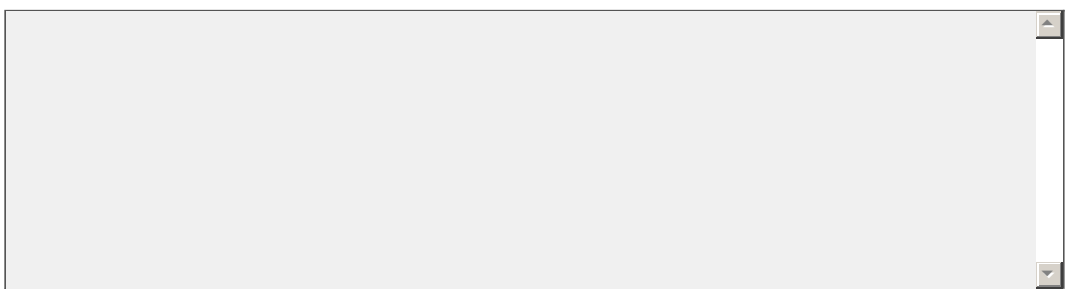

11. Overall, using a scale from 1-10 (1=lowest, $10=$ highest satisfaction), rate how satisfied you were with the overall reference assistance you received using e-mail.
O
$\bigcirc 2$
$\mathrm{O}_{3}$
$\mathrm{O}_{4}$
$\bigcirc$
$\bigcirc 6$
$\mathrm{O}_{7}$
O 8
$\bigcirc 9 \bigcirc_{\text {(highest) }} 10$

Please elaborate on why you rated as you did. 


\section{Appendix D. Telephone Online Survey}

\section{Telephone Format}

Please give us your feedback on receiving assistance via telephone by answering the following questions.

\section{*1. Your Name:}

2. To which university library did you direct your questions for this study?

University A

University B

*3. Please copy and paste the first question that you asked.

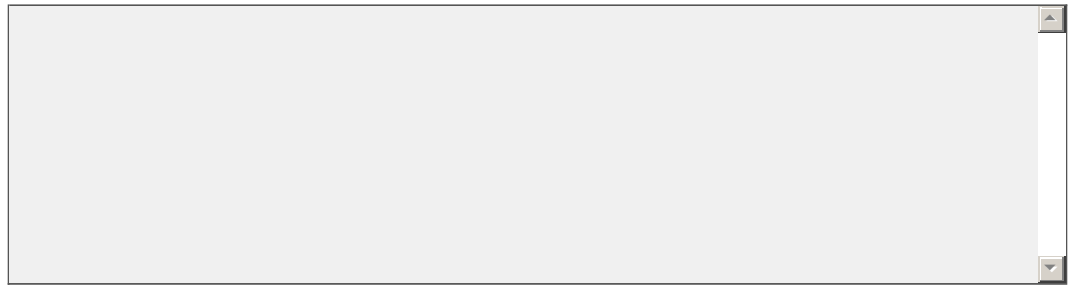

4. Please provide a general description of the answer you received to question 1 in the form below:

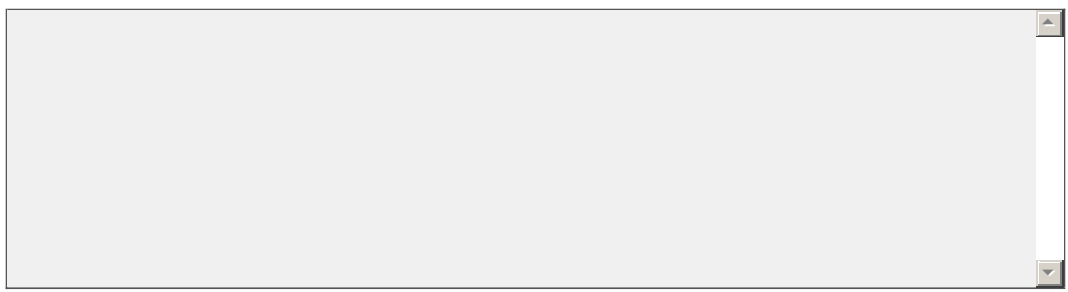

5. Approximately how long, from start-to-finish, did it take for your question to be answered?
Less than 1 minute
1-5 minutes
6-10 minutes
11-15 minutes
16-30 minutes
31-60 minutes
1-2 hours
$2+$ hours 


\section{Appendix D. Telephone Online Survey}

\section{Telephone Format}

6. On a scale from 1-10 ( $1=$ lowest, $10=$ highest satsifaction), rate how satisfied you were with the overall experience in getting your first question answered.

$\bigcirc_{1} \bigcirc \bigcirc_{2} \bigcirc 3 \bigcirc_{4} \bigcirc 5 \bigcirc_{6} \bigcirc 7 \bigcirc_{7}$

Please elaborate on why you rated as you did (quicker/slower response than expected; response was adequate; general comfort level in asking question, etc.):

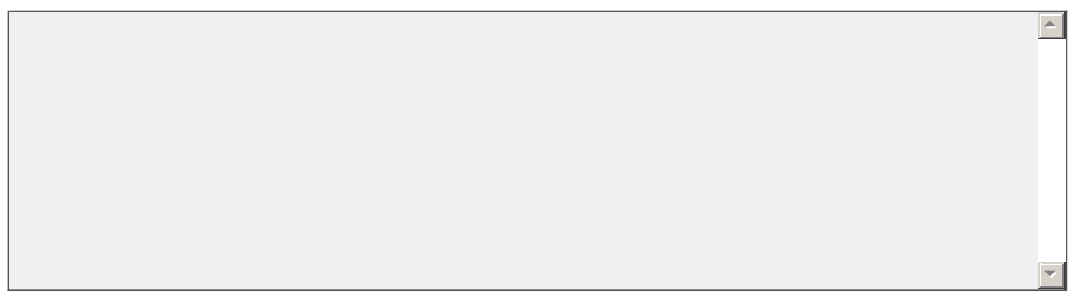

*7. Please copy and paste the second question that you asked.

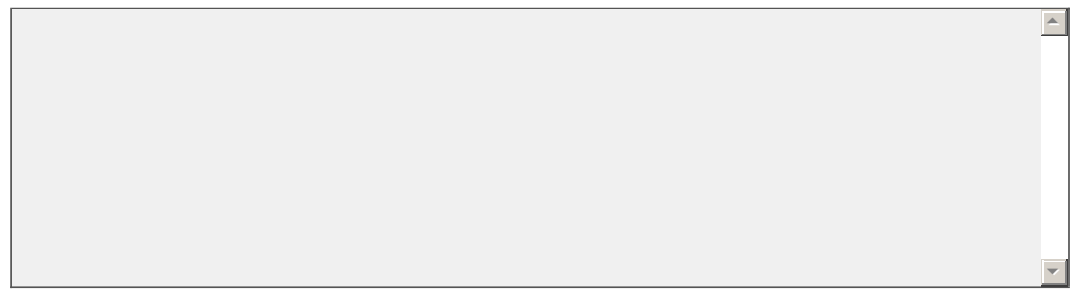

8. Please provide a general description of the answer you received to question 2 in the form below:

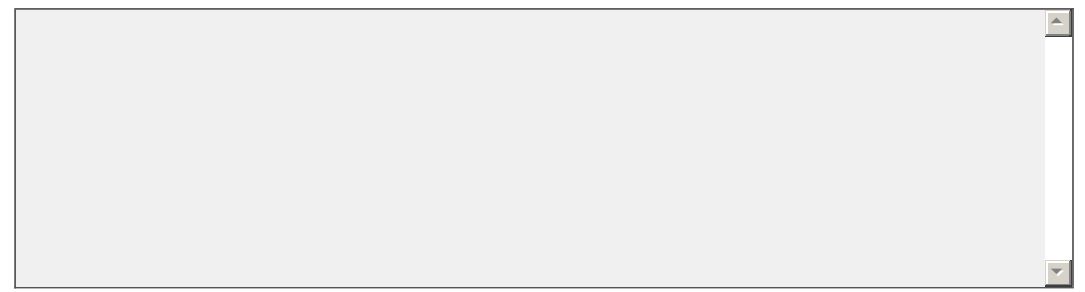




\section{Appendix D. \\ Telephone Online Survey}

\section{Telephone Format}

9. Approximately how long, from start to finish, did it take for your question to be answered?
Less than 1 minute
1-5 minutes
6-10 minutes
11-15 minutes
16-30 minutes
31-60 minutes
1-2 hours
2+ hours

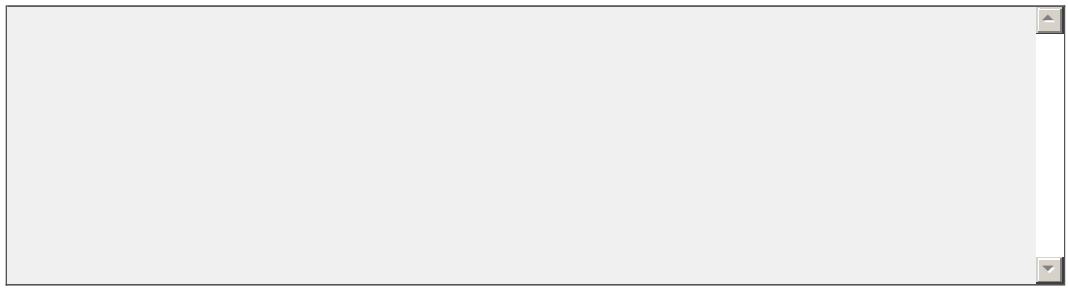

10. On a scale from 1-10 (1=lowest, $10=$ highest satsifaction), rate how satisfied you were with the overall experience in getting your second question answered.
$\mathrm{O}_{1}$
$\mathrm{O}_{2}$
3
$\bigcirc_{4} \bigcirc$
O
$\mathrm{O}_{7}$
O
$\bigcirc$
$\bigcirc_{\text {(highest) }} 10$

Please elaborate on why you rated as you did (quicker/slower response than expected; response was adequate; general comfort level in asking question, etc.):

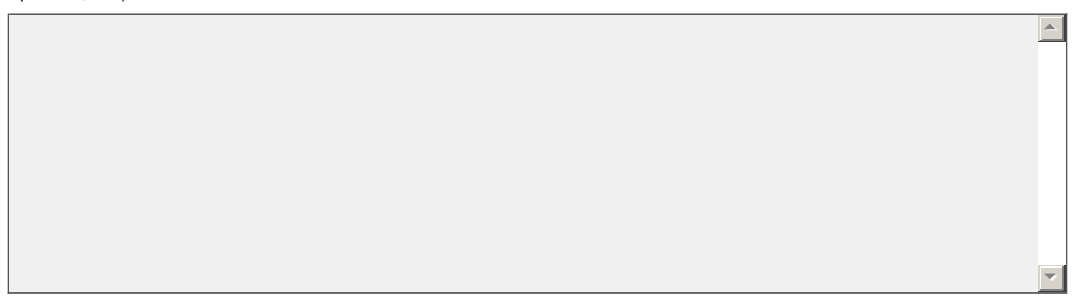




\section{Appendix D. \\ Telephone Online Survey}

1. Telephone Format

11. Overall, using a scale from 1-10 (1=lowest, 10 =highest satsifaction), rate how satisfied you were with the overall reference assistance you received using the telephone.

$\bigcirc_{\text {(lowest) }} \bigcirc_{2} \quad \bigcirc_{3} \quad \bigcirc_{4} \quad \bigcirc_{5} \quad \bigcirc_{6} \quad \bigcirc_{7} \quad \bigcirc_{8} \quad \bigcirc_{9} \bigcirc_{\text {(highest) }}$

Please elaborate on why you rated as you did:

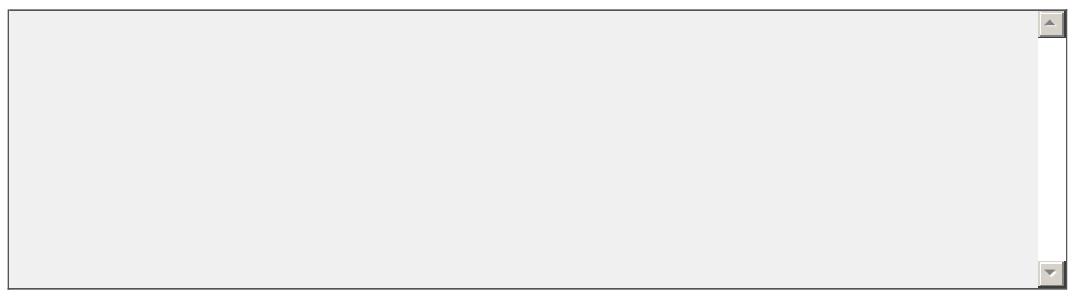

12. How did the assistance you received via telephone compare overall compare to the e-mail format?
Overall, I liked telephone more than e-mail
About the same
Overall, I liked telephone less than e-mail

Please elaborate on your comparison between the two: 
A Usability Evaluation of Academic Virtual Reference Services 333

\section{Appendix E. Chat Online Survey}

\section{Chat Format}

Please give us your feedback on receiving assistance via chat by answering the following questions.

\section{*1. Your Name:}

2. To which university library did you direct your questions for this study?

University A

University B

*3. Please copy and paste the first question that you asked.

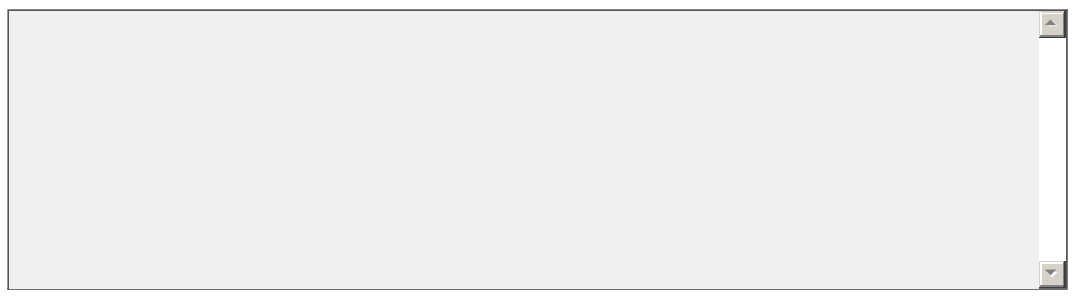

4. Please provide the full text of the response you received via chat and/or a general description of the answer you received to question 1 in the form below:

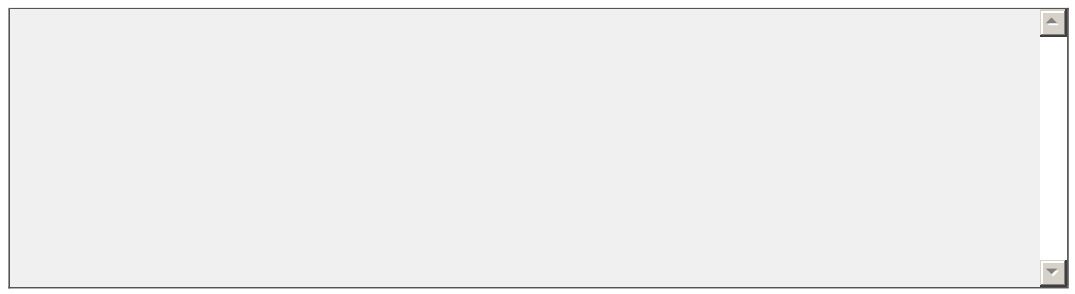




\section{Appendix E. Chat Online Survey}

\section{Chat Format}

5. Approximately how long, from start to finish, did it take for your question to be answered?
Less than 1 minute
1-5 minutes
6-10 minutes
11-15 minutes
16-30 minutes
31-60 minutes
1-2 hours
2+ hours

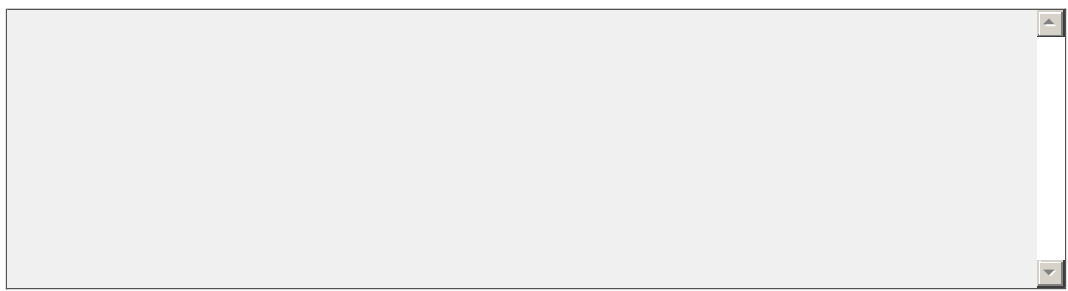

6. On a scale from 1-10 (1=lowest, 10=highest satsifaction), rate how satisfied you were with the overall experience in getting your first question answered.

$\bigcirc_{\text {(lowest) }} \bigcirc_{2} \bigcirc_{3} \bigcirc_{4} \bigcirc_{5} \quad \bigcirc_{6} \quad \bigcirc_{7} \bigcirc 8 \bigcirc_{9} \bigcirc_{\text {(highest) }}$

Please elaborate on why you rated as you did (quicker/slower response than expected; response was adequate; general comfort level in asking question, etc.): 
A Usability Evaluation of Academic Virtual Reference Services 335

\section{Appendix E. \\ Chat Online Survey}

\section{Chat Format}

* 7. Please copy and paste the second question that you asked.

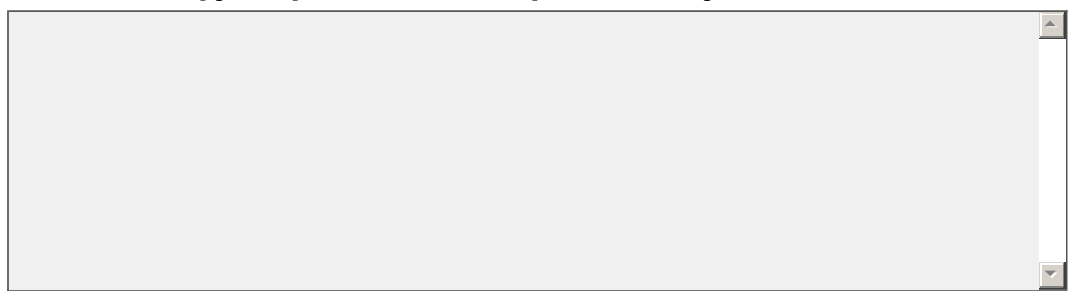

8. Please provide the full text of the response you received via chat and/or a general description of the answer you received to question 2 in the form below:

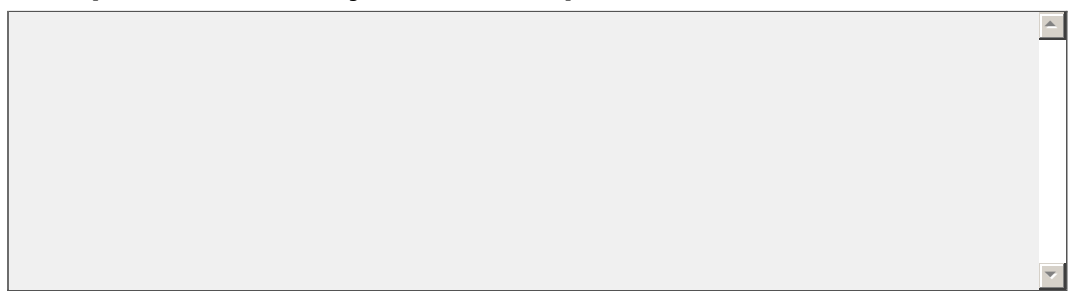

9. Approximately how long, from start to finish, did it take for your question to be answered?
Less than 1 minute
1-5 minutes
6-10 minutes
○11-15 minutes
(16-30 minutes
31-60 minutes
1-2 hours
2+ hours 
336 College \& Research Libraries

May 2014

Appendix E.

Chat Online Survey

1. Chat Format

10. On a scale from 1-10 (1=lowest, 10=highest satsifaction), rate how satisfied you were with the overall experience in getting your second question answered.

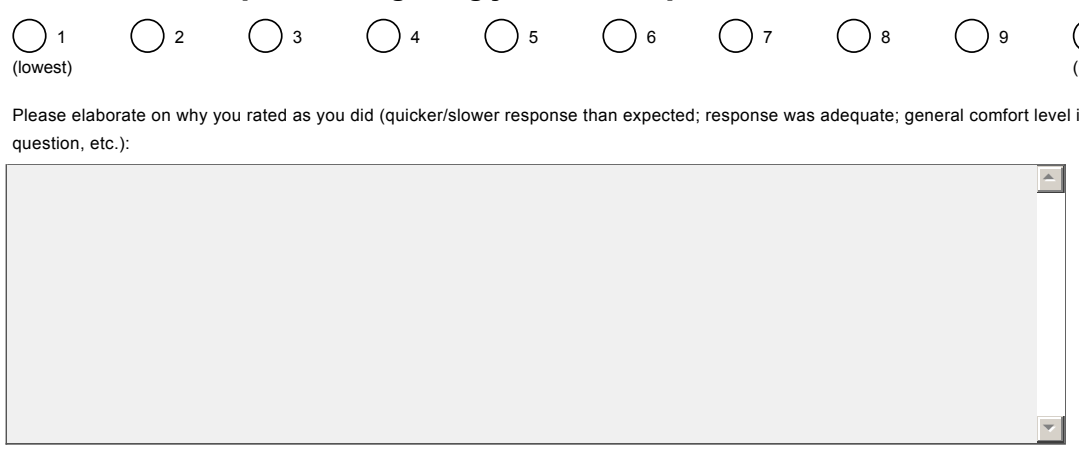

11. Overall, using a scale from 1-10 (1=lowest, 10 =highest satsifaction), rate how satisfied you were with the overall reference assistance you received using chat.

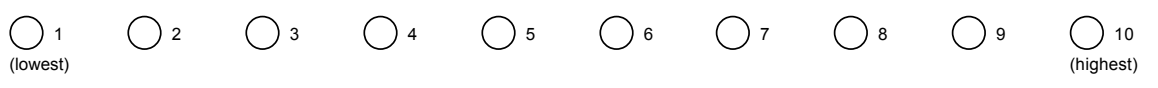

Please elaborate on why you rated as you did: 
A Usability Evaluation of Academic Virtual Reference Services 337

\section{Appendix E. Chat Online Survey}

\section{Chat Format}

12. How did the assistance you received via chat compare overall to e-mail?

Overall, I liked chat more than e-mail

About the same

Overall, I liked chat less than e-mail

Please elaborate on your comparison between the two:

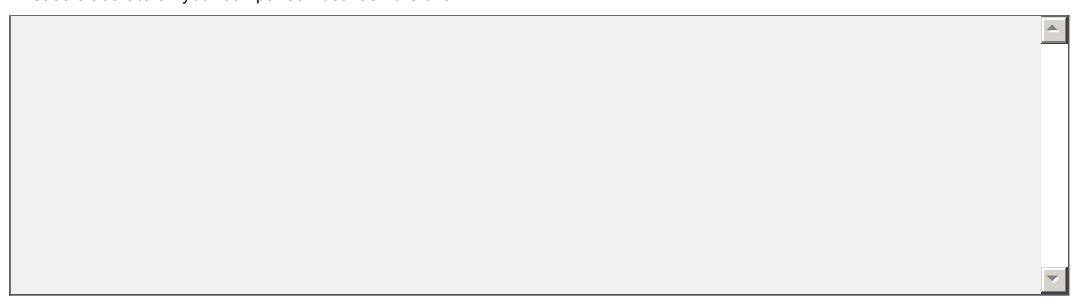

13. How did the assistance you received via chat compare overall to telephone?

Overall, I liked chat more than telephone

$\bigcirc$ About the same

Overall, I liked chat less than telephone

Please elaborate on your comparison between the two:

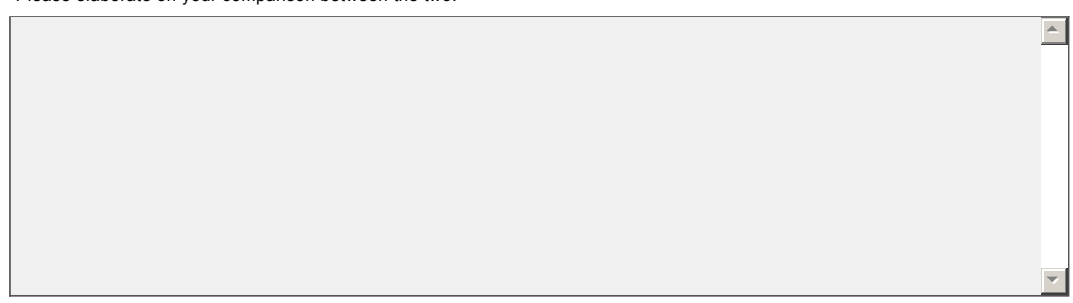




\section{Appendix F. Skype Online Survey}

\section{Skype Format}

Please give us your feedback on receiving assistance via Skype by answering the following questions.

\section{*1. Your Name:}

2. To which university library did you direct your questions for this study?

University A

University B

*3. Please copy and paste the first question that you asked.

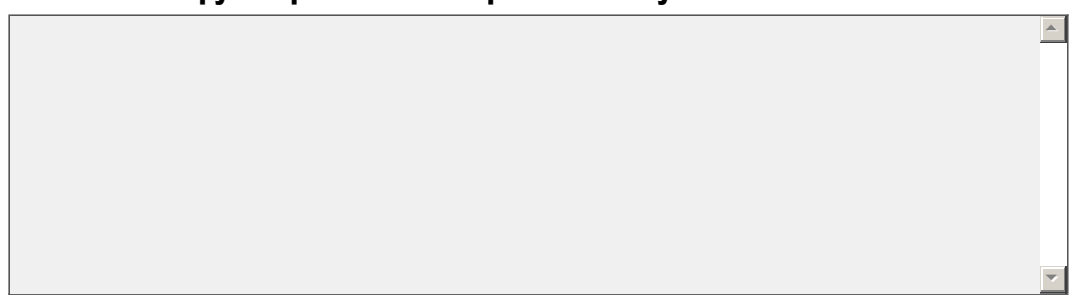

4. Please provide a general description of the answer you received to question 1 in the form below:

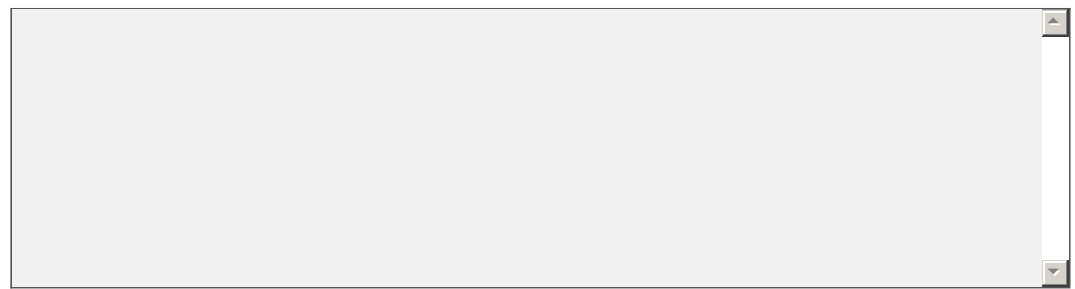


A Usability Evaluation of Academic Virtual Reference Services 339

\section{Appendix F. Skype Online Survey}

\section{Skype Format}

5. Approximately how long, from start to finish, did it take for your question to be answered?
Less than 1 minute
1-5 minutes
6-10 minutes
11-15 minutes
16-30 minutes
31-60 minutes
1-2 hours
2+ hours

Please elaborate if you would like to:

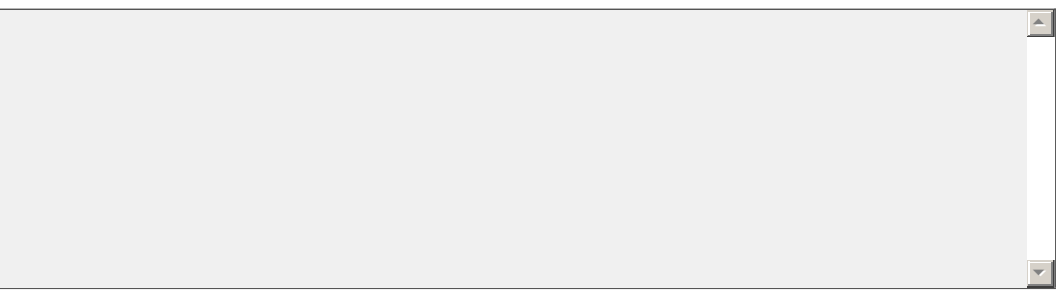

6. On a scale from 1-10 (1=lowest, 10 =highest satsifaction), rate how satisfied you were with the overall experience in getting your first question answered.
$\bigcirc 1$
$\bigcirc 2$
$\bigcirc_{3}$
$\mathrm{O}_{4}$
O 5
O
$\mathrm{O}_{7}$
8
○9 $\bigcirc_{\text {(highest) }} 10$

Please elaborate on why you rated as you did (quicker/slower response than expected; response was adequate; general comfort level in asking question, etc.): 


\section{Appendix F. Skype Online Survey}

\section{Skype Format}

*7. Please copy and paste the second question that you asked.

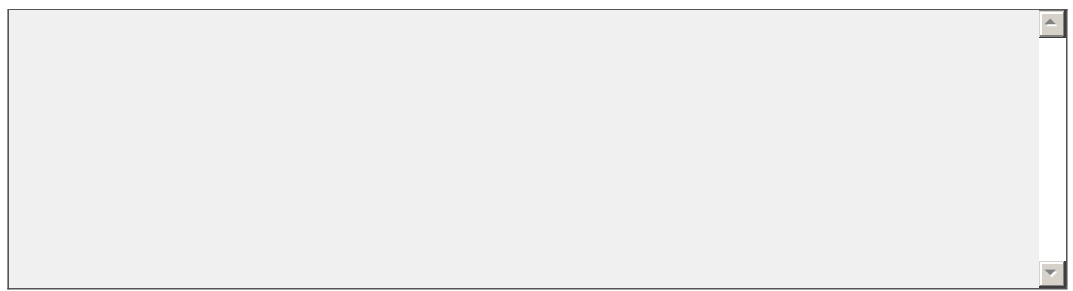

8. Please provide a general description of the answer you received to question 2 in the form below:

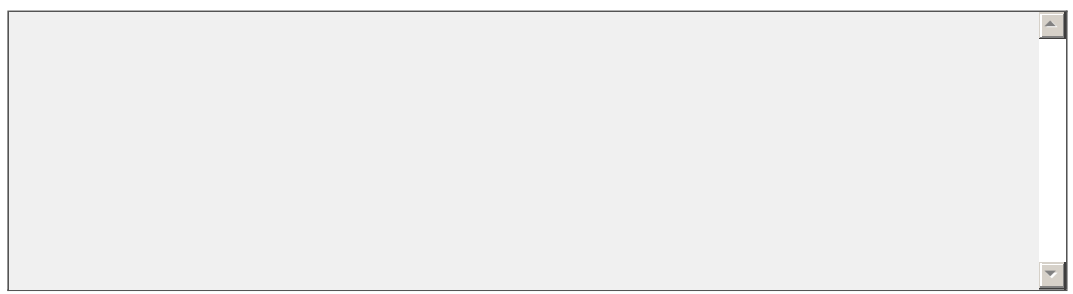

9. Approximately how long, from start to finish, did it take for your question to be answered?
Less than 1 minute
1-5 minutes
6-10 minutes
○11-15 minutes
○16-30 minutes
31-60 minutes
○1-2 hours
2+ hours 


\section{Appendix F. Skype Online Survey}

\section{Skype Format}

10. On a scale from 1-10 (1=lowest, $10=$ highest satsifaction), rate how satisfied you were with the overall experience in getting your second question answered.

$\bigcirc_{\text {(lowest) }} \bigcirc_{2} \bigcirc_{3} \quad \bigcirc_{4} \quad \bigcirc_{5} \quad \bigcirc_{6} \quad \bigcirc_{7} \quad \bigcirc_{8} \quad \bigcirc_{9} \quad \bigcirc_{\text {(highest) }}$

Please elaborate on why you rated as you did (quicker/slower response than expected; response was adequate; general comfort level in asking question, etc.):

11. Overall, using a scale from $1-10$ (1=lowest, $10=$ highest satsifaction), rate how satisfied you were with the overall reference assistance you received using Skype.
$\bigcirc$
$\bigcirc_{2} \bigcirc_{3}$
$\mathrm{O}_{4}$
${ }_{5}$
O
$\mathrm{O}_{7}$
○
$\bigcirc$
$\bigcirc 10$
(lowest)

Please elaborate on why you rated as you did

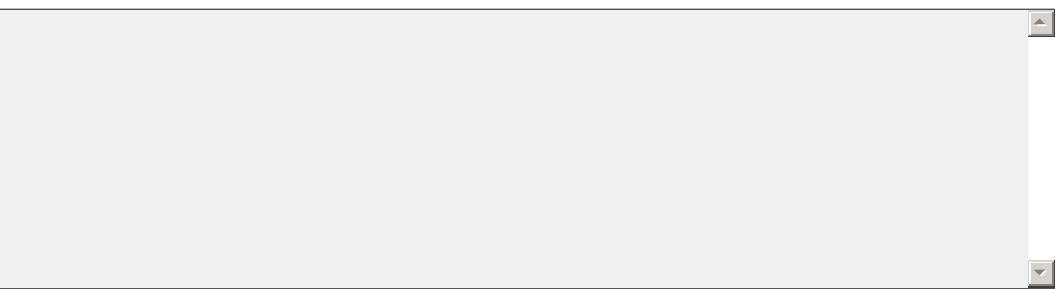

12. How did the assistance you received via Skype compare overall to e-mail?

Overall, I liked Skype more than e-mail

About the same

$\bigcirc$ Overall, I liked Skype less than e-mail 


\section{Appendix F. Skype Online Survey}

\section{Skype Format}

13. How did the assistance you received via Skype compare overall to telephone?

Overall, I liked Skype more than telephone

About the same

Overall, I liked Skype less than telephone

Please elaborate on your comparison between the two:

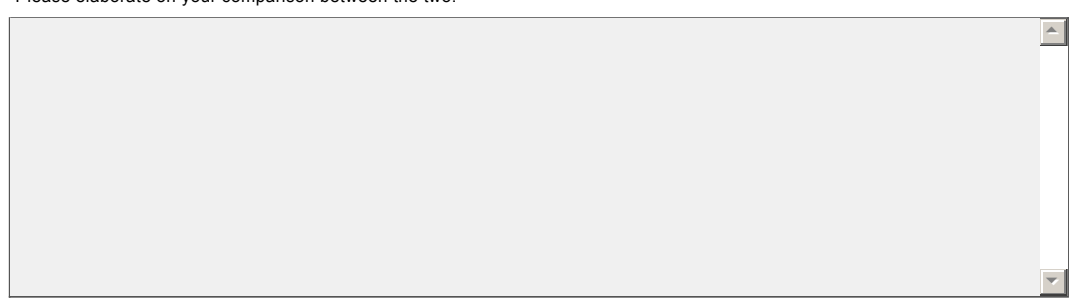

14. How did the assistance you received via Skype compare overall to chat?

Overall, I liked Skype more than chat

About the same

Overall, I liked Skype less than chat

Please elaborate on your comparison between the two (i.e. Did being able to see and hear the person help or hinder the process?):

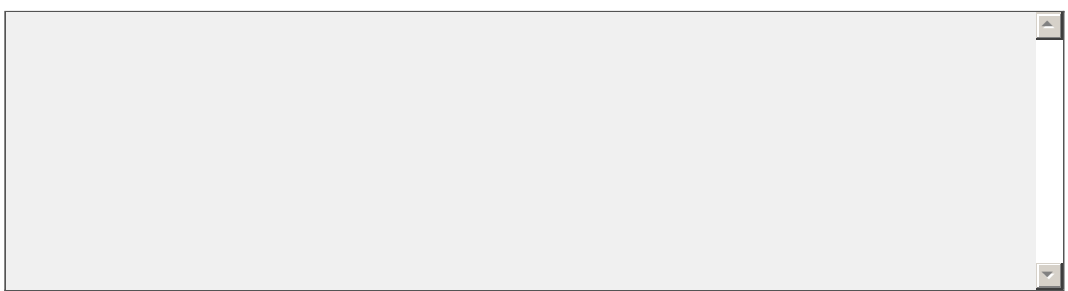


A Usability Evaluation of Academic Virtual Reference Services 343

\section{Appendix G. Text Online Survey}

\section{Text Messaging Format}

Please give us your feedback on receiving assistance via Text Messaging by answering the following questions.

\section{*1. Your Name:}

2. To which university library did you direct your questions for this study?

University A

University B

* 3. Please copy and paste the first question that you asked.

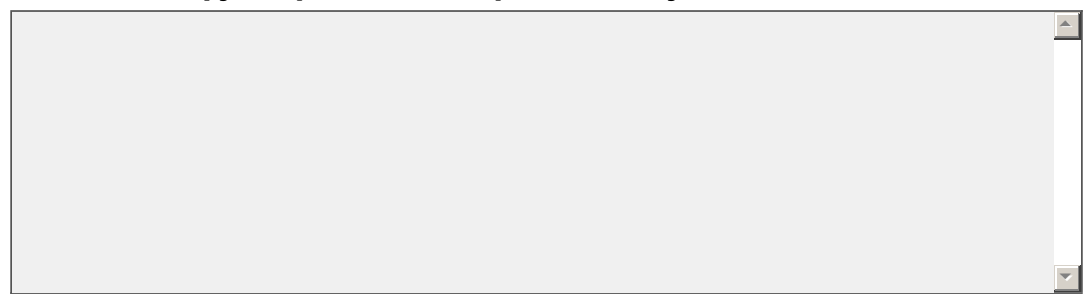

4. Please provide a general description of the answer you received to question 1 in the form below:

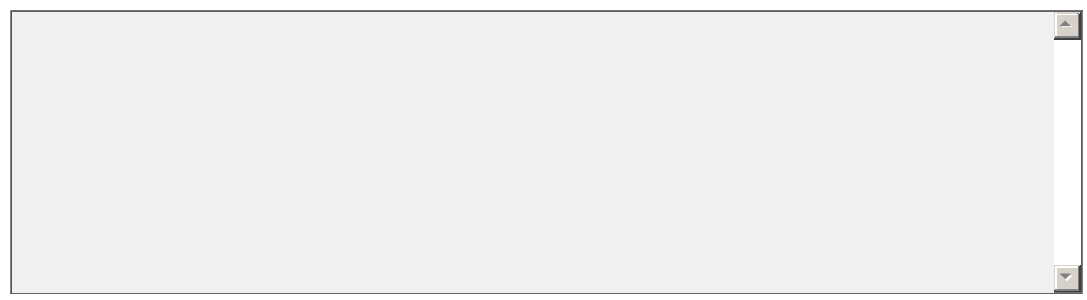




\section{Appendix G. Text Online Survey}

\section{Text Messaging Format}

5. Approximately how long, from start to finish, did it take for your question to be answered?
Less than 1 minute
○1-5 minutes
6-10 minutes
11-15 minutes
16-30 minutes
31-60 minutes
1-2 hours
$2+$ hours

Please elaborate if you would like to:

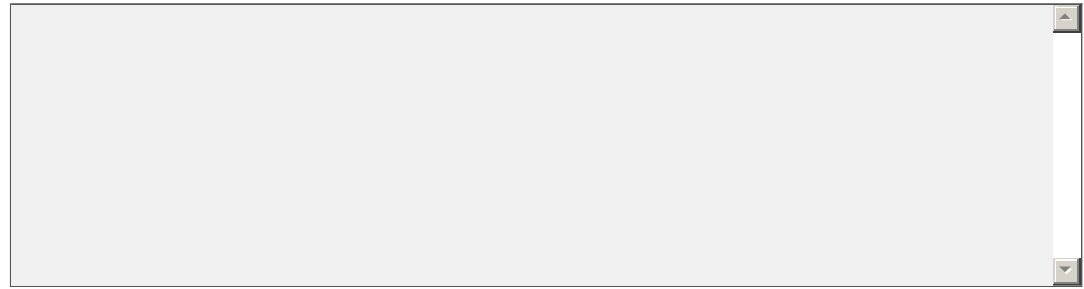

6. On a scale from 1-10 (1=lowest, $10=$ highest satisfaction), rate how satisfied you were with the overall experience in getting your first question answered.

$\bigcirc_{1} \bigcirc 2 \bigcirc 3 \bigcirc_{3} \bigcirc_{4} \bigcirc 5 \bigcirc_{6} \bigcirc_{7}$

Please elaborate on why you rated as you did (quicker/slower response than expected; response was adequate; general comfort level in asking question, etc.):

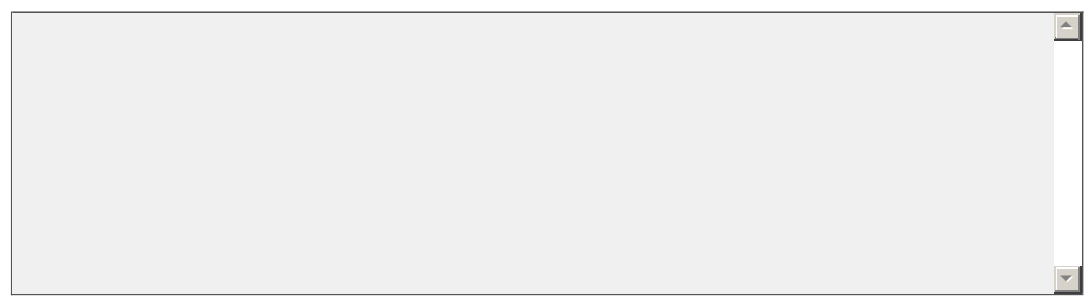

* 7. Please copy and paste the second question that you asked.

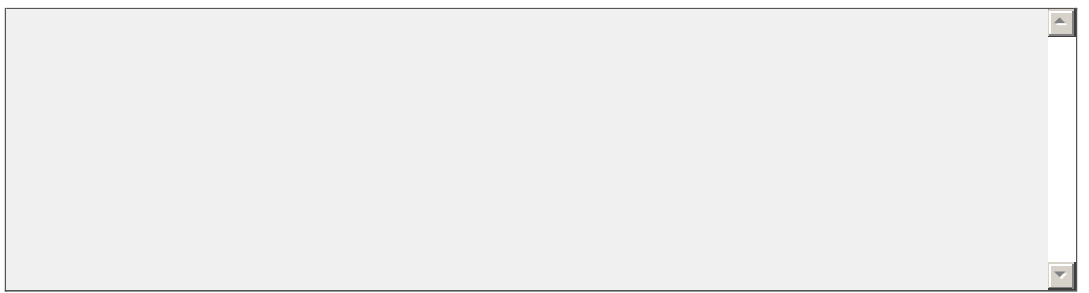


A Usability Evaluation of Academic Virtual Reference Services 345

\section{Appendix G. Text Online Survey}

\section{Text Messaging Format}

8. Please provide a general description of the answer you received to question 2 in the form below:

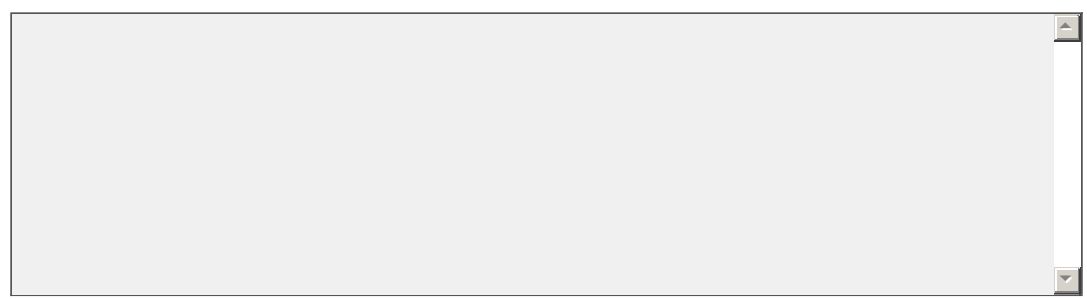

9. Approximately how long, from start to finish, did it take for your question to be answered?
Less than 1 minute
1-5 minutes
6-10 minutes
$\bigcirc 11-15$ minutes
16-30 minutes
31-60 minutes
1-2 hours
$2+$ hours

10. On a scale from 1-10 (1=lowest, 10=highest satsifaction), rate how satisfied you were with the overall experience in getting your second question answered.
$\bigcirc 1$
$\bigcirc 2$
${ }_{3}$
${ }_{4}$
5
O 6
${ }_{7}$
○
$\bigcirc$
${ }_{10}$
(lowest)

Please elaborate on why you rated as you did (quicker/slower response than expected; response was adequate; general comfort level in asking question, etc.): 


\section{Appendix G. Text Online Survey}

\section{Text Messaging Format}

11. Overall, using a scale from 1-10 (1=lowest, 10=highest satsifaction), rate how satisfied you were with the overall reference assistance you received using Text Messaging.
$\bigcirc 1$
$\bigcirc 2$
$\bigcirc 3$
$\mathrm{O}_{4}$
${ }_{5}$
○
${ }_{7}$
8
$\bigcirc \bigcirc_{\text {(highest) }} 10$

Please elaborate on why you rated as you did:

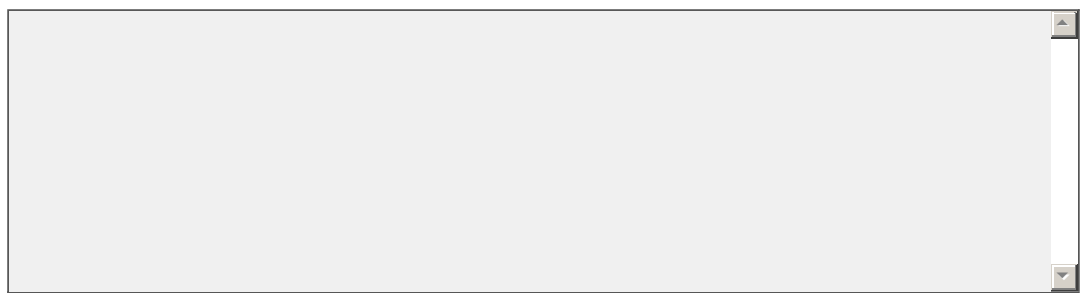

12. How did the assistance you received via Text Messaging compare overall to e-mail?

$\bigcirc$ Overall, I liked Text Messaging more than e-mail

About the same

Overall, I liked Text Messaging less than e-mail

Please elaborate on your comparison between the two:

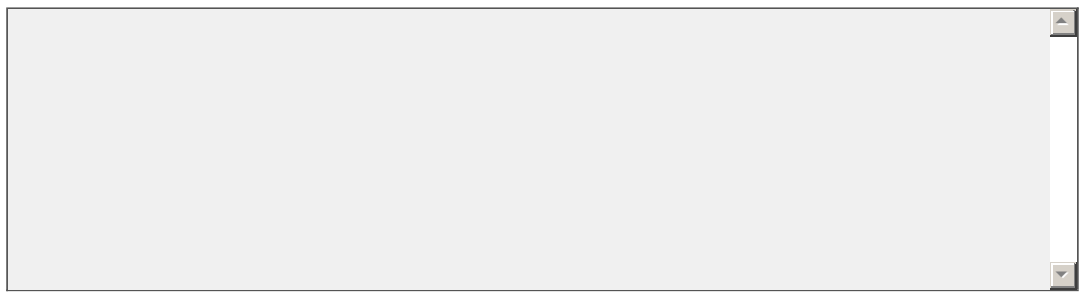

13. How did the assistance you received via Text Messaging compare overall to telephone?

Overall, I liked Text Messaging more than telephone

About the same

Overall, I liked Text Messaging less than telephone

Please elaborate on your comparison between the two:

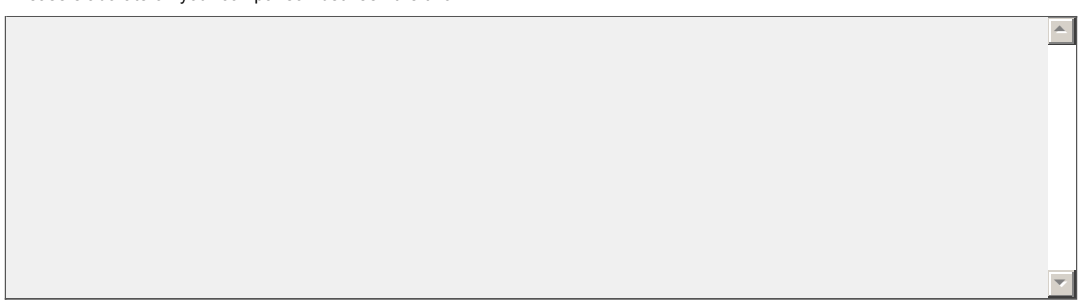


A Usability Evaluation of Academic Virtual Reference Services 347

\section{Appendix G. Text Online Survey}

1. Text Messaging Format

14. How did the assistance you received via Text Messaging compare overall to chat?

Overall, I liked Text Messaging more than chat

About the same

Overall, I liked Text Messaging less than chat

Please elaborate on your comparison between the two (i.e. Did being able to see and hear the person help or hinder the process?):

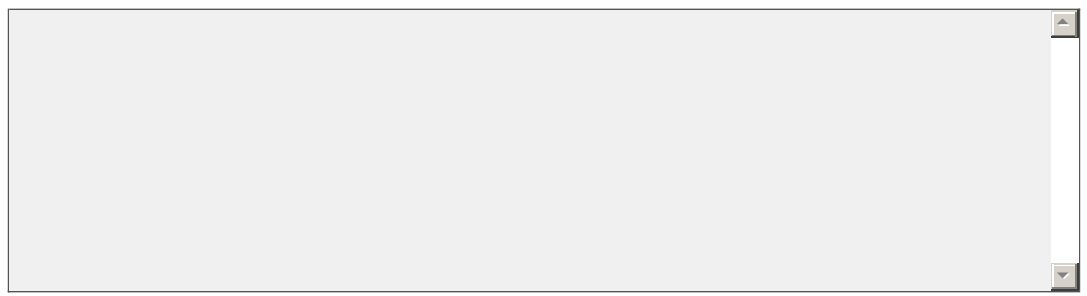

15. How did the assistance you received via Text Messaging compare overall to Skype?

Overall, I liked Text Messaging more than Skype

About the same

Overall, I liked Text Messaging less than Skype

Please elaborate on your comparison between the two (i.e. Did being able to see and hear the person help or hinder the process?):

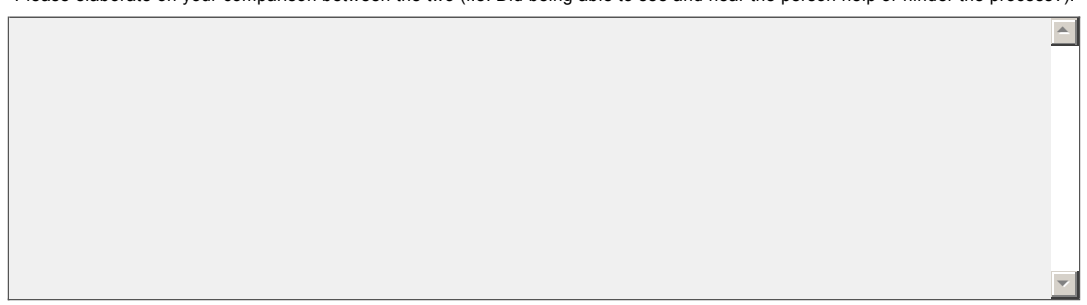




\section{Appendix $\mathrm{H}$. Debriefing Usability Survey}

\section{Reference Services Usability and Satisfaction Survey (Master)}

\section{*1. Your Name:}

\section{*2. Please indicate your academic status.}

Undergraduate

Graduate

3. To which university library did you direct your questions for this study?

$\bigcirc$ University $A$

$\bigcirc$ University B

\section{What is your gender?}

Male

$\bigcirc$ Female

5. What is your age?
Under 24
25-34
35-44
45-54
55-64
65 and up

\section{What is your ethnicity?}
white
Black
Hispanic/Latino
$\bigcirc$ Asian/Pacific Islander
Native American
$\bigcirc$ Multiracial 
A Usability Evaluation of Academic Virtual Reference Services 349

\section{Appendix $\mathrm{H}$. Debriefing Usability Survey}

\section{Reference Services Usability and Satisfaction Survey (Master)}

7. Please rate your overall experience with each of the five formats (in general).

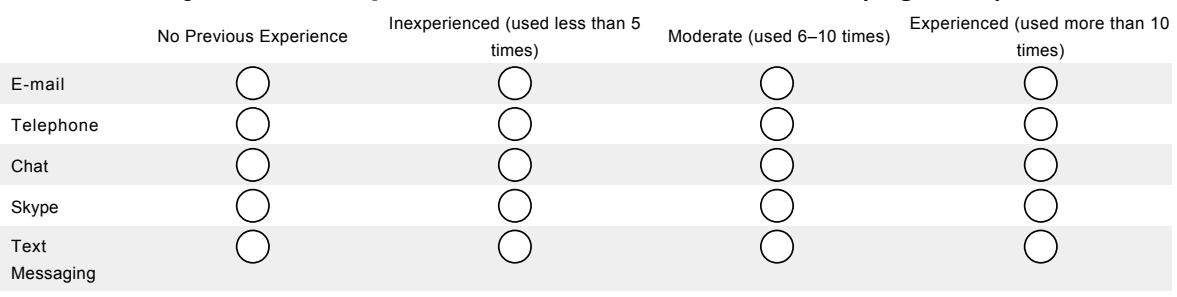

Please feel free to elaborate:

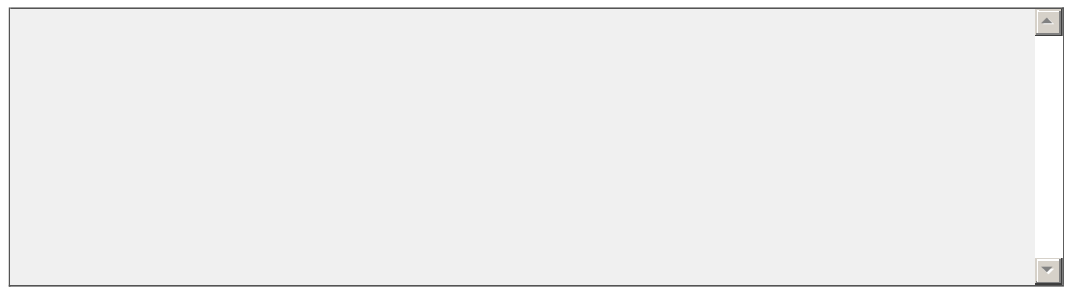

Please rate the use of e-mail on the following usability factors.

1. Effectiveness is defined as the extent to which a goal or task is reached. Rate your overall experience with both e-mail reference questions/answers on the following factors:

Satisfaction Rating

Task Completion (Were you able to successfully use e-mail to ask your questions and have them answered?)

Quality of Output (How satisfied were you with the overall quality of the e-mail responses and the extent to which they answered your questions?)

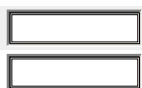

Please elaborate on why you rated each as you did: 


\section{Appendix $\mathrm{H}$. Debriefing Usability Survey}

\section{Reference Services Usability and Satisfaction Survey (Master)}

2. Efficiency is defined as the amount of effort required to reach your goal. Rate your overall satisfaction with both e-mail reference questions/answers on the following factors:

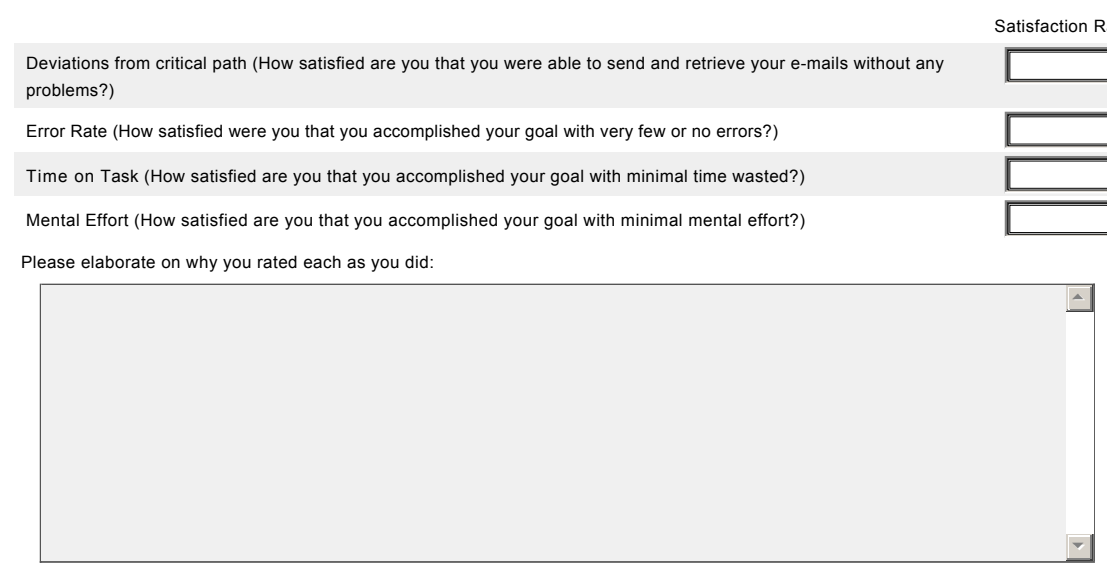

3. Satisfaction is your overall level of comfort in being able to attain your goals. Rate your overall satisfaction with both e-mail reference questions/answers:

Satisfaction Rating

Overall, how satisfied were you with the general usability of using e-mail to ask reference questions?

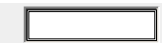

Please elaborate on why you rated each as you did:

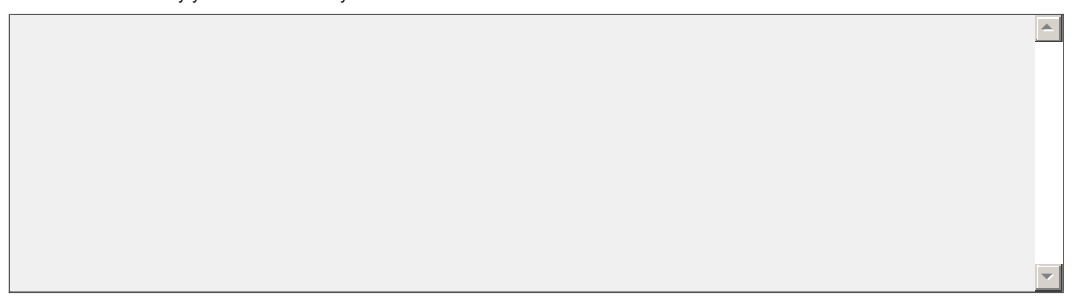

4. In having the two reference questions answered across e-mail, what was your PRIMARY SOURCE for access to computer technology?

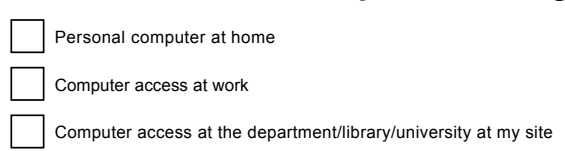

Feel free to elaborate: 


\section{Appendix $\mathrm{H}$. \\ Debriefing Usability Survey}

\section{Reference Services Usability and Satisfaction Survey (Master)}

5. Please add any further comments about your perceptions of using e-mail.

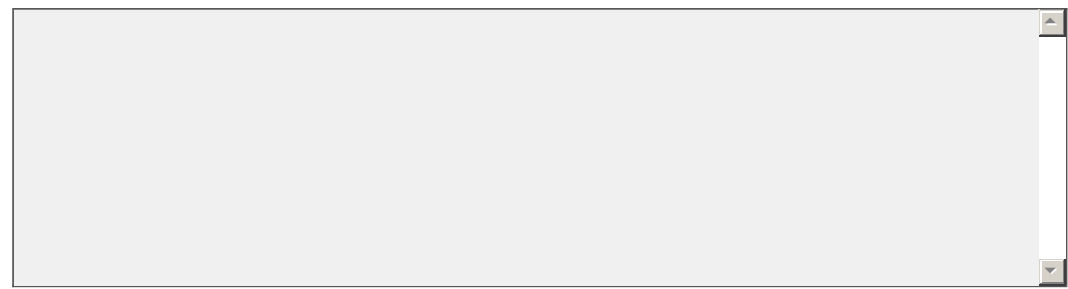

Please rate the use of the telephone on the following usability factors.

1. Effectiveness is defined as the extent to which a goal or task is reached. Rate your overall experience with both telephone reference questions/answers on the following factors:

Satisfaction Rating

Task Completion (Were you able to successfully use telephone to ask your questions and have them answered?)

Quality of Output (How satisfied were you with the overall quality of the telephone responses and the extent to which they answered your questions?)

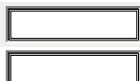

Please elaborate on why you rated each as you did:

2. Efficiency is defined as the amount of effort required to reach your goal. Rate your overall satisfaction with both telephone reference questions/answers on the following factors:

Satisfaction Rating

Deviations from critical path (How satisfied are you that you were able to use telephone reference without any problems?)

Error Rate (How satisfied were you that you accomplished your goal with very few or no errors?)

Time on Task (How satisfied are you that you accomplished your goal with minimal time wasted?)

Mental Effort (How satisfied are you that you accomplished your goal with minimal mental effort?)

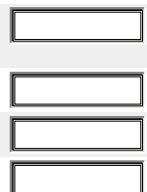

Please elaborate on why you rated each as you did: 


\section{Appendix $\mathrm{H}$. Debriefing Usability Survey}

\section{Reference Services Usability and Satisfaction Survey (Master)}

3. Satisfaction is your overall level of comfort in being able to attain your goals. Rate your overall satisfaction with both telephone reference questions/answers:

Overall, how satisfied were you with the general usability of using telephone to ask reference questions?

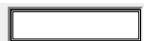

Please elaborate on why you rated each as you did:

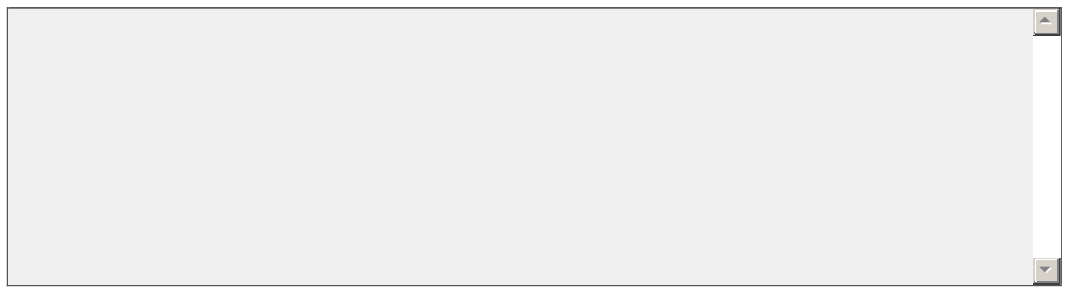

4. What type of telephone did you use to ask the reference questions?
$\square$ My cell phone
My home telephone
My work telephone
Other Wireless Device

5. Please add any further comments about your perceptions of using the telephone.

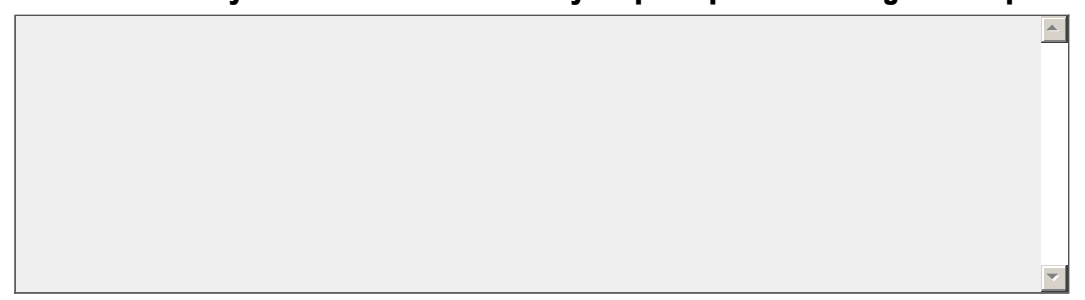

Please rate the use of Chat on the following usability factors.

1. Effectiveness is defined as the extent to which a goal or task is reached. Rate your overall experience with both chat reference questions/answers on the following factors:

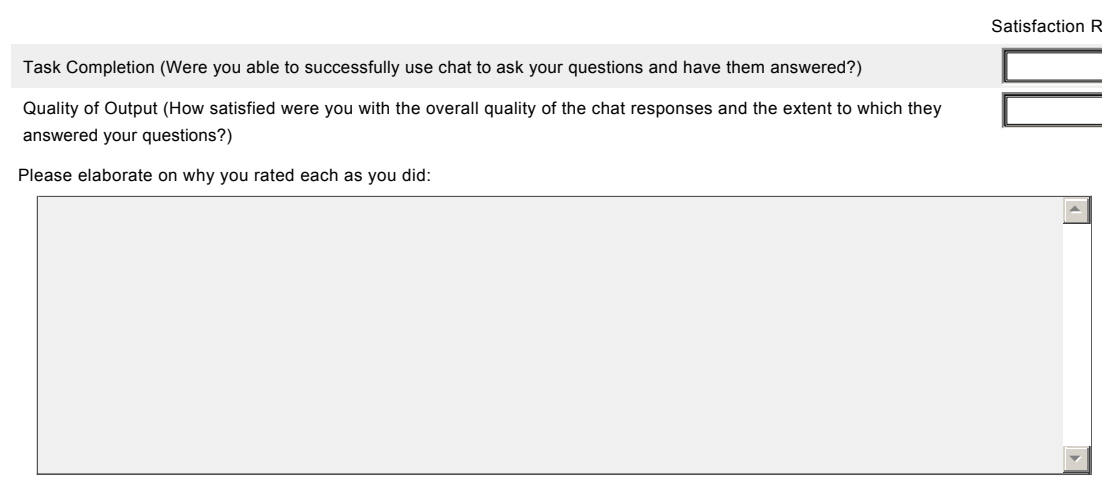




\section{Appendix $\mathrm{H}$. Debriefing Usability Survey}

\section{Reference Services Usability and Satisfaction Survey (Master)}

2. Efficiency is defined as the amount of effort required to reach your goal. Rate your overall satisfaction with both chat reference questions/answers on the following factors:

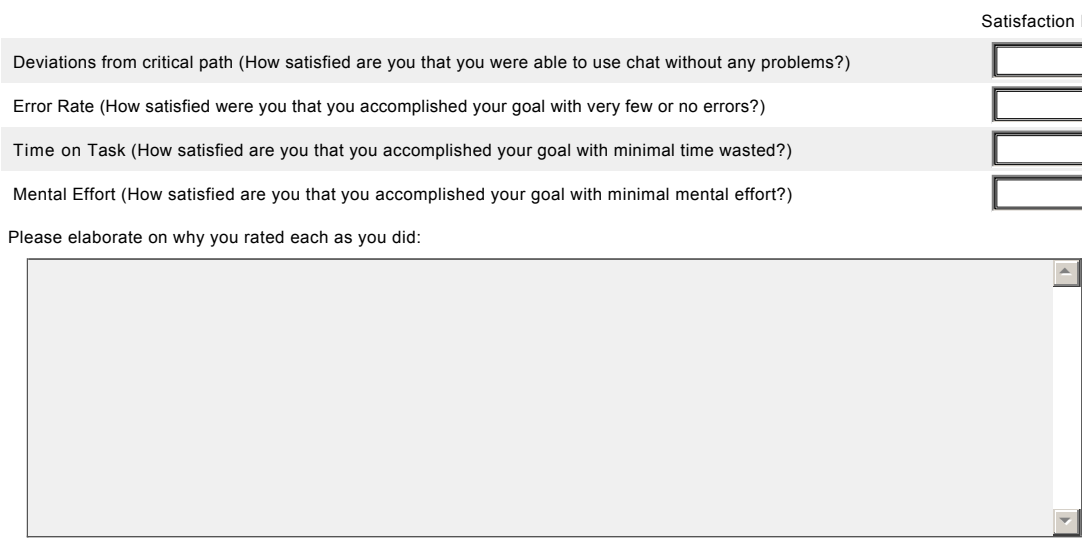

3. Satisfaction is your overall level of comfort in being able to attain your goals. Rate your overall satisfaction with both your chat reference questions/answers:

Satisfaction Rating

Overall, how satisfied were you with the general usability of using chat to ask reference questions?

Please elaborate on why you rated each as you did:

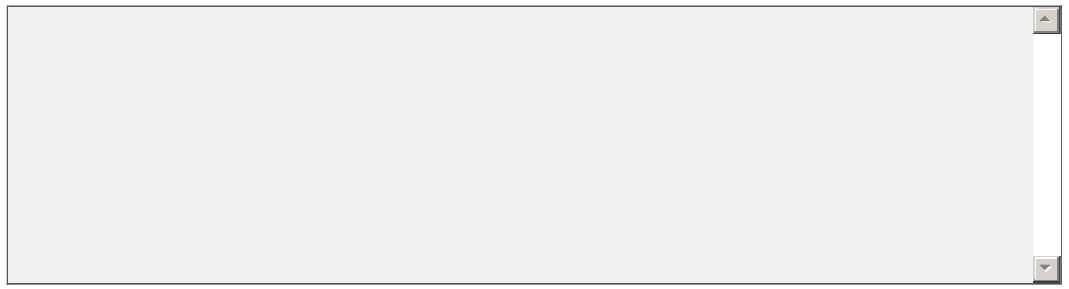

4. In having the two reference questions answered in chat, what was your PRIMARY SOURCE for access to computer technology?

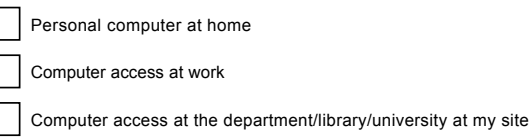




\section{Appendix $\mathrm{H}$. Debriefing Usability Survey}

\section{Reference Services Usability and Satisfaction Survey (Master)}

5. Please add any further comments about your perceptions of using chat.

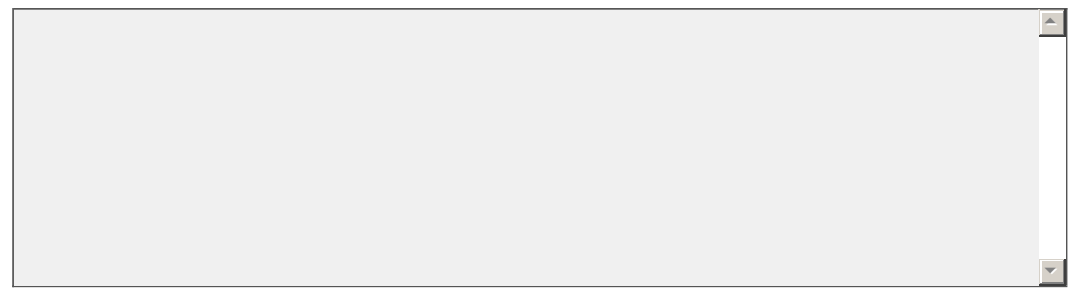

Please rate the use of Skype on the following usability factors.

1. Effectiveness is defined as the extent to which a goal or task is reached. Rate your overall experience with both Skype reference questions/answers on the following factors:

Satisfaction Rating

Task Completion (Were you able to successfully use Skype to ask your questions and have them answered?)

Quality of Output (How satisfied were you with the overall quality of the Skype responses and the extent to which they answered your questions?)

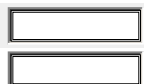

Please elaborate on why you rated each as you did:

2. Efficiency is defined as the amount of effort required to reach your goal. Rate your overall satisfaction with both Skype reference questions/answers on the following factors:

Deviations from critical path (How satisfied are you that you were able to use Skype without any problems?) Error Rate (How satisfied were you that you accomplished your goal with very few or no errors?)

Time on Task (How satisfied are you that you accomplished your goal with minimal time wasted?)

Mental Effort (How satisfied are you that you accomplished your goal with minimal mental effort?)

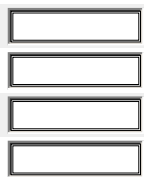

Please elaborate on why you rated each as you did: 


\section{Appendix $\mathrm{H}$. Debriefing Usability Survey}

\section{Reference Services Usability and Satisfaction Survey (Master)}

3. Satisfaction is your overall level of comfort in being able to attain your goals. Rate your overall satisfaction with both your Skype reference questions/answers:

Satisfaction Rating

Overall, how satisfied were you with the general usability of using Skype to ask reference questions?

Please elaborate on why you rated each as you did:

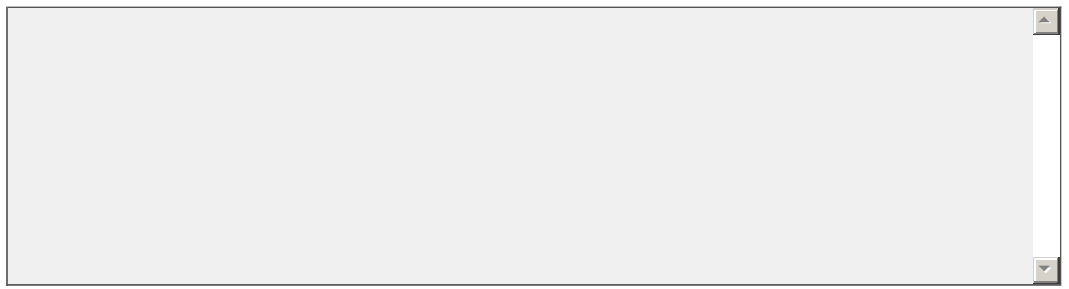

4. In having the two reference questions answered in chat, what was your PRIMARY SOURCE for access to computer technology?

Personal computer at home

Computer access at work

Computer access at the department/library/university at my site

Feel free to elaborate:

5. Please add any further comments about your perceptions of using Skype.

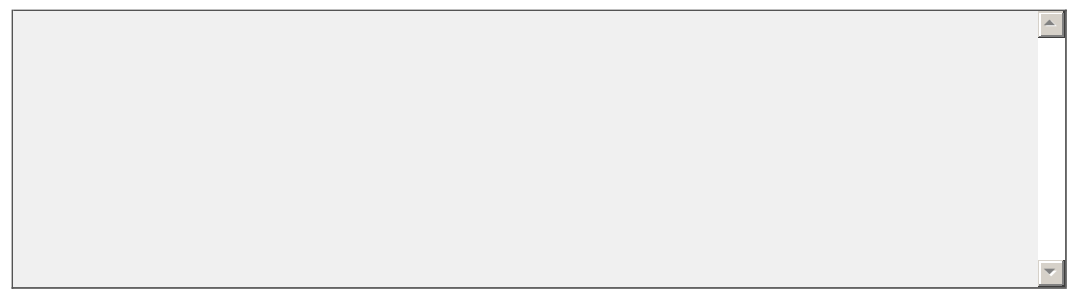

Please rate the use of Text Messaging on the following usability factors.

1. Effectiveness is defined as the extent to which a goal or task is reached. Rate your overall experience with both Text Messaging reference questions/answers on the following factors.

Task Completion (Were you able to successfully use Text Messaging to ask your questions and have them answered?)

Quality of Output (How satisfied were you with the overall quality of the Text Messaging responses and the extent to which they answered your questions?)

Please elaborate on why you rated each as you did. 


\section{Appendix $\mathrm{H}$. Debriefing Usability Survey}

\section{Reference Services Usability and Satisfaction Survey (Master)}

2. Efficiency is defined as the amount of effort required to reach your goal. Rate your overall satisfaction with both Text Messaging reference questions/answers on the following factors:

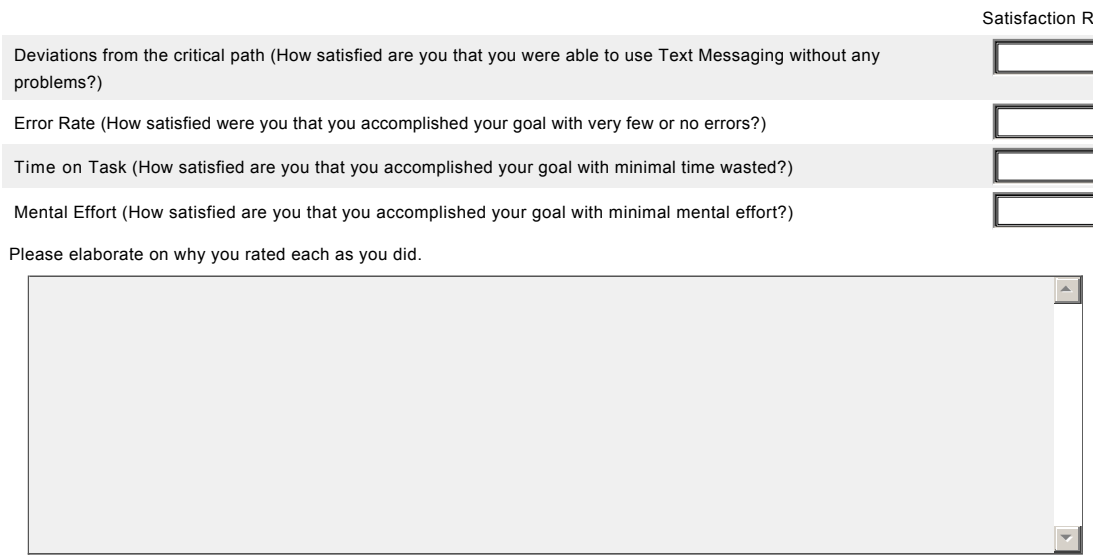

3. Satisfaction is your overall level of comfort in being able to attain your goals. Rate your overall satisfaction with both your Text Messaging reference questions/answers.

Overall, how satisfied were you with the general usability of using Text Messaging to ask reference questions?

Please elaborate on why you rated each as you did.

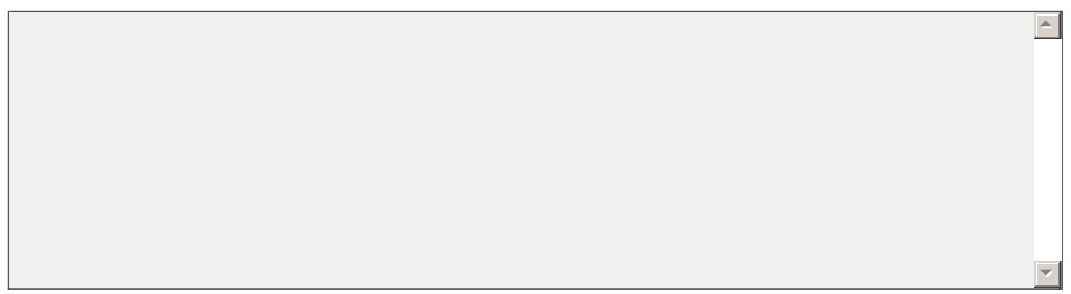

4. What type of device did you use to ask the reference questions?

My cell phone

Other wireless device 


\section{Appendix $\mathrm{H}$. \\ Debriefing Usability Survey}

\section{Reference Services Usability and Satisfaction Survey (Master)}

5. Please add any further comments about your perceptions of using Text Messaging.

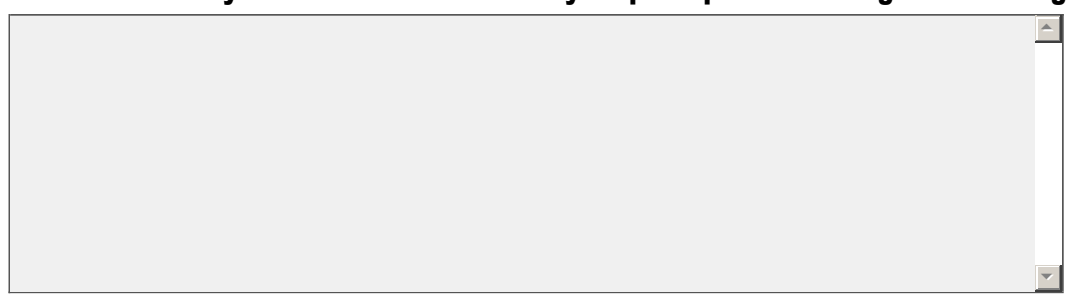

Please rank order your preference of formats based on Question 1 and Question 2.

1. Based on Question 1 only, rank-order (1=highest, $5=$ lowest) the five formats based on your preference.

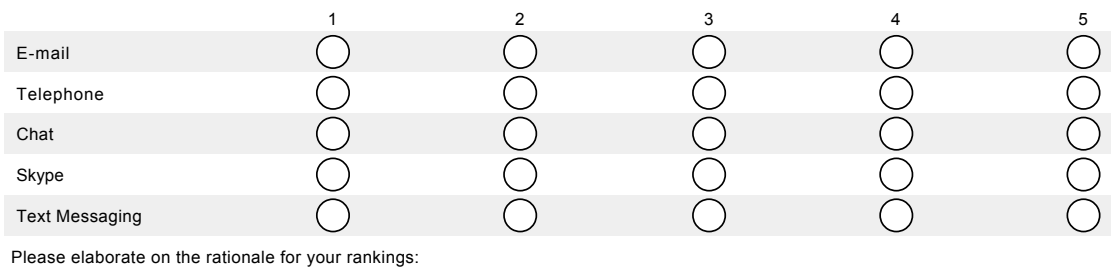

Please elaborate on the rationale for your rankings: 


\section{Appendix $\mathrm{H}$. Debriefing Usability Survey}

\section{Reference Services Usability and Satisfaction Survey (Master)}

2. Based on Question 2 only, rank-order (1=highest, 5=lowest) the five formats based on your preference.
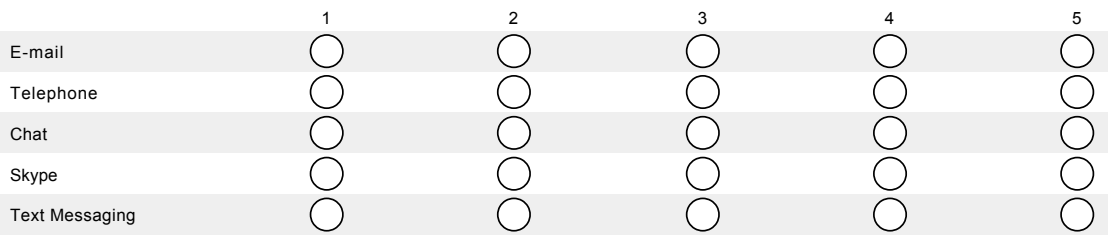

Please elaborate on the rationale for your rankings:

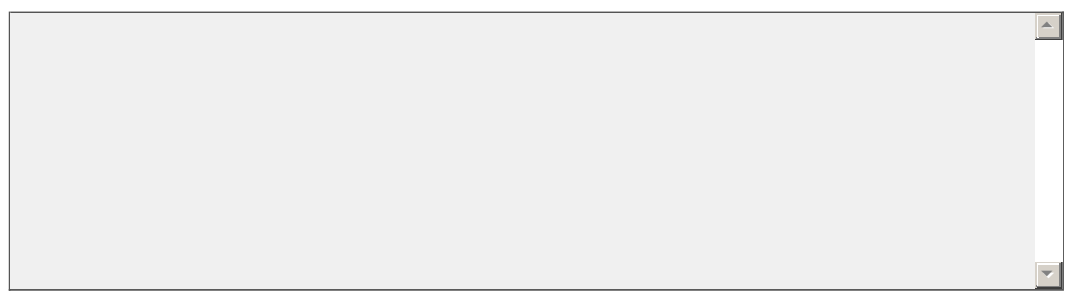

3. If you decided to get reference help locating materials for a research project (example: locating biographical information for an author without using Google), which ONE of the following options for assistance would you most likely choose first?
Face-to-Face Consultation
Telephone Consultation
E-mail Reference
Online Chat Reference
$\bigcirc$ Skype Video Reference
$\bigcirc$ Text-a-Librarian Reference
Other 


\section{Appendix $\mathrm{H}$. \\ Debriefing Usability Survey}

\section{Reference Services Usability and Satisfaction Survey (Master)}

4. If you needed help finding a quick fact (example: finding the hours for the library for the week), which ONE of the following options for assistance would you most likely choose first?

Face-to-Face Consultation
Telephone Consultation
E-mail Reference
Online Chat Reference
Skype Video Reference
Text-a-Librarian Reference
Other

Please feel free to elaborate:

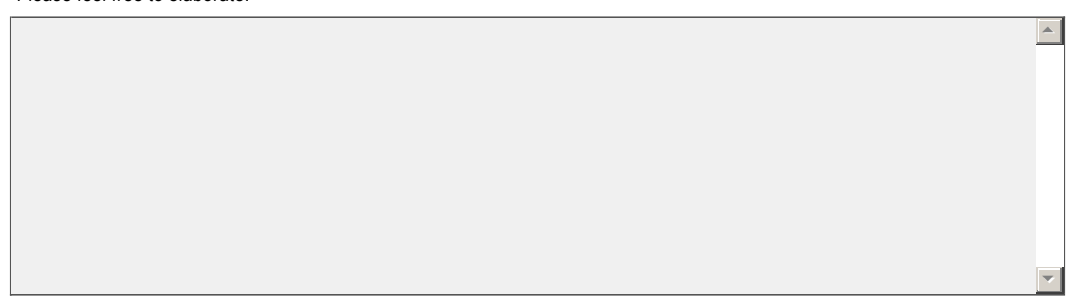

5. Please feel free to leave us any other comments or thoughts you may have about this project.

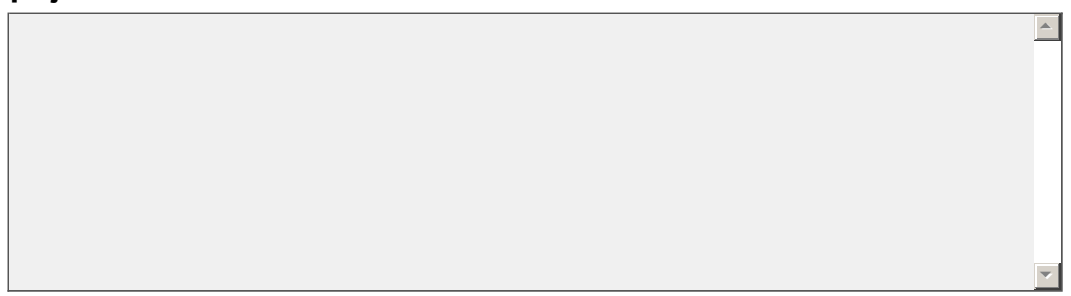

Thank you very much for participating in our project. For more information please contact Dr. Anthony Chow at aschow@uncg.edu. 


\section{Notes}

1. Anthony S. Chow and Rebecca A. Croxton, "Information-Seeking Behavior and Reference Medium Preferences: Differences between Faculty, Staff, and Students," Reference \& User Services Quarterly 51, no. 33 (2012): 246.

2. Bernie Sloan, "Twenty Years of Virtual Reference," Internet Reference Services Quarterly 11, no. 2 (2006): 91-95.

3. Anthony S. Chow et al., "What Is a Usable Library Website? Results from a Nationwide Survey" (under review), Reference and User Services Quarterly.

4. Laura K. Probst, “Digital Reference Management: A Penn State Case Study," Internet Reference Services Quarterly 10, no. 2 (2005): 43-59.

5. Michel C. Atlas, "Library Anxiety in the Electronic Era, or Why Won't Anybody Talk to Me Anymore?" Reference \& User Services Quarterly 44, no. 4 (2005): 314-19; R. David Lankes, "Virtual Reference to Participatory Librarianship: Expanding the Conversation," Bulletin of the American Society for Information Science and Technology 34, no. 2 (2008): 11-14; Marie L. Radford and M. Kathleen Kern, "A Multiple-Case Study Investigation of the Discontinuation of Nine Chat Reference Services," Library \& Information Science Research 28 (2006): 521-47.

6. Lynn S. Connaway, Marie L. Radford, and Timothy J. Dickey, "On the Trail of the Elusive Non-user: What Research in Virtual Reference Environments Reveals," ASISET Bulletin 34, no. 2 (2008): 25-28.

7. Anthony S. Chow, “The Usability of Digital Information Environments: Planning, Design, and Assessment," in Chandos Digital Information Review, eds. W. Evans and D. Baker (Cambridge: Chandos, 2012).

8. The International Organization for Standardization 9241-11, "Ergonomic Requirements for Office Work with Visual Display Terminals (VDTs), Part II: Guidance on Usability" (Geneva, Switzerland, 1998).

9. Xiangming Mu et al., "A Survey and Empirical Study of Virtual Reference Service in Academic Libraries," Journal of Academic Librarianship 37, no. 2 (Mar. 2011): 126.

10. Char Booth, "Developing Skype-Based Reference Services," Internet Reference Services Quarterly 13, no. 2 \& 3 (2008): 148; Kelly M. Broughton, "Usage and User Analysis of a RealTime Digital Reference Services," The Reference Librarian 38, no. 29 (2002); Chow and Croxton, "Information-Seeking Behavior and Reference Medium Preferences"; Joel Cummings, Lara Cummings, and Linda Frederiksen, "User Preferences in Reference Services: Virtual Reference and Academic Libraries," portal: Libraries and the Academy, 7, no. 1 (Jan. 2007): 81-96; Christina M. Desai, “Instant Messaging Reference: How Does It Compare?" Electronic Library 21, no. 1 (2003); J.B. Hill, Cherie M. Hill, and Dayne Sherman, "Text Messaging in an Academic Library: Integrating SMS into Digital Reference," The Reference Librarian 47, no. 1 (2007); Nora Hillyer and Linda L. Parker, "Video Reference-It's Not Your Typical Virtual Reference: Video Reference Services at the University of Nebraska at Omaha," Internet Reference Services Quarterly 11, no. 4 (2006): 41-54.

11. Chow and Croxton, "Information-Seeking Behavior and Reference Medium Preferences."

12. Chow, "The Usability of Digital Information Environments."

13. Jesse J. Garrett, The Elements of the User Experience: User-centered Design for the Web and Beyond, 2nd ed. (Berkeley, CA.: New Riders, 2011).

14. Cheryl Dee and Maryellen Allen, "A Survey of the Usability of Digital Reference Services on Academic Health Science Library Websites," The Journal of Academic Librarianship 32, no. 1 (2006): 69-78.

15. Chow and Croxton, "Information-Seeking Behavior and Reference Medium Preferences."

16. Jakob Nielsen, “Usability 101: Introduction to Usability," www.useit.com/alertbox/20030825. html (accessed June 18, 2012, last modified 2012).

17. Chow and Croxton, "Information-Seeking Behavior and Reference Medium Preferences"; Jeffrey Pomerantz and Lili Luo, "Motivation and Uses: Evaluating Virtual Reference from the Users' Perspective," Library \& Information Research 28 (2006): 5-29; Marie L. Radford et al., "Evaluating E-Reference: Transforming Digital Reference through Research and Evaluation," Proceedings of the American Society for Information Science and Technology 45, no. 1 (2009): 1-11; David Ward, "Why Users Choose Chat: A Survey of Behavior and Motivations," Internet Reference Services Quarterly 10, no. 1 (2005): 29-46. 251.

18. Chow and Croxton, "Information-Seeking Behavior and Reference Medium Preferences,"

19. Lynn S. Connaway, Timothy J. Dickey, and Marie L. Radford, “If It Is Too Inconvenient I'm Not Going after It: Convenience as a Critical Factor in Information-Seeking Behaviors," Library E Information Science Research 33 (2011): 185.

20. Chow and Croxton, "Information-Seeking Behavior and Reference Medium Preferences," 253. 
21. Desai, "Instant Messaging Reference"; Pomerantz and Luo, "Motivation and Uses"; Radford et al., "E-valuating E-Reference."

22. Hill, Hill, and Sherman, "Text Messaging in an Academic Library," 24.

23. Ibid., 26.

24. Booth, "Developing Skype-Based Reference Services," 160.

25. Dee and Allen, "A Survey of the Usability of Digital Reference Services."

26. Beth Thomsett-Scott, "If You Ask, I Will Tell You: Future Users of Virtual Reference Share Their Thoughts on the Design, Operation, and Marketing of Virtual Reference," in The Virtual Experience: Integrating Theory into Practice, eds. R. David Lankes, Joseph Janes, Linda C. Smith, and Christina M. Finneran. (New York: Neal-Schuman, 2004): 63-86.

27. Claire Warwick et al., "Cognitive Economy and Satisficing in Information Seeking: A Longitudinal Study of Undergraduate Information Behavior," Journal of the American Society for Information Science E Technology 60 (2009): 2409.

28. Joseph Janes, “Digital Reference: Reference Librarians' Experiences and Attitudes," Journal of the American Society for Information Science and Technology 53 (2002): 549-66; I.J. Lee, "Do Virtual Reference Librarians Dream of Virtual Reference Questions? A Qualitative and Quantitative Analysis of Email and Chat Reference," Australian Academic and Research Libraries 35 (2004): 95-110; Joseph E. Straw, "A Virtual Understanding: The Reference Interview and Question Negotiation in the Digital Age," Reference \& User Services Quarterly 39 (2000): 376-79; Jo Kibbee, David Ward, and Wei Ma, "Virtual Reference, Real Data: Results of a Pilot Study," Reference Services Review 30, no. 1 (2002): 35-36; Kirsti Nilsen, "The Library Visit Study: User Experiences at the Virtual Reference Desk," Information Research 9, no. 2 (2004), available online at http://informationr.net/ ir/9-2/paper171.html [accessed 7 January 2013].

29. Wendy Diamond and Barbara Pease, “Digital Reference: A Case Study of Question Types in an Academic Library," Reference Services Review 29 (2001): 210-19; S.M. Gray, "Virtual Reference Services: Directions and Agendas," Reference \& User Services Quarterly 39 (2000): 367-75.

30. David Ward, "Measuring the Completeness of Reference Transactions in Online Chats: Results of an Unobtrusive Study," Reference E User Services Quarterly 44 (2004): 46-56.

31. Nahyun Kwon, "Public Library Patrons' Use of Collaborative Chat Reference Service: The Effectiveness of Question Answering by Question Type," Library E Information Science Research 29 (2007): 70-91.

32. Lee, "Do Virtual Reference Librarians Dream of Virtual Reference Questions?"

33. Hill, Hill, and Sherman, "Text Messaging in an Academic Library," 25.

34. Chow and Croxton, "Information-Seeking Behavior and Reference Medium Preferences."

35. Marguerite Reardon, "Text Messaging Explodes in America," CBS News, available online at www.cbsnews.com/stories/2008/09/23/teh/cnettechnews/main4471183.shtml [accessed 20 June 2012, last modified 2 April 2009].

36. Booth, "Developing Skype-Based Reference Services," 157.

37. Ibid.; Chow and Croxton, "Information-Seeking Behavior and Reference Medium Preferences."

38. Ward, "Why Users Choose Chat," 37.

39. Chow and Croxton, "Information-Seeking Behavior and Reference Medium Preferences," 257.

40. Ibid.

41. Herbert Poole, Theories of the Middle Range (Norwood, N.J.: Ablex, 1985).

42. Nancy J. Young and Marilyn Von Seggern, "General Information Seeking in Changing Times: A Focus Group Study," Reference E User Services Quarterly 41, no. 2 (Winter 2001): 159-69.

43. Chow and Croxton, "Information-Seeking Behavior and Reference Medium Preferences."

44. Patrick Jordan, An Introduction to Usability (Philadelphia, Pa.: Taylor \& Francis, 1998).

45. Warwick et al., "Cognitive Economy and Satisficing in Information Seeking."

46. Poole, Theories of the Middle Range. 